\title{
Effect of Chitosan Coating on PLGA Nanoparticles for Oral Delivery of Thymoquinone: In Vitro, Ex Vivo, and Cancer Cell Line Assessments
}

\author{
Sultan Alshehri ${ }^{1,2}{ }^{\oplus}$, Syed Sarim Imam ${ }^{1, *}{ }^{(0)}$, Md Rizwanullah ${ }^{3}\left(\mathbb{D}\right.$, Khalid Umar Fakhri ${ }^{4}{ }^{(}$, \\ Mohd Moshahid Alam Rizvi ${ }^{4}$, Wael Mahdi ${ }^{1}$ (D) and Mohsin Kazi ${ }^{1}$ (D)
}

check for updates

Citation: Alshehri, S.; Imam, S.S.; Rizwanullah, M.; Fakhri, K.U.; Rizvi, M.M.A.; Mahdi, W.; Kazi, M. Effect of Chitosan Coating on PLGA Nanoparticles for Oral Delivery of Thymoquinone: In Vitro, Ex Vivo, and Cancer Cell Line Assessments. Coatings 2021, 11, 6. https://doi.org/ $10.3390 /$ coatings 11010006

Received: 8 November 2020 Accepted: 21 December 2020 Published: 23 December 2020

Publisher's Note: MDPI stays neutral with regard to jurisdictional clai$\mathrm{ms}$ in published maps and institutional affiliations.

Copyright: (C) 2020 by the authors. Licensee MDPI, Basel, Switzerland. This article is an open access article distributed under the terms and conditions of the Creative Commons Attribution (CC BY) license (https:// creativecommons.org/licenses/by/ $4.0 /)$.
1 Department of Pharmaceutics, College of Pharmacy, King Saud University, Riyadh 11451, Saudi Arabia; salshehri1@ksu.edu.sa (S.A.); wmahdi@ksu.edu.sa (W.M.); mkazi@ksu.edu.sa (M.K.)

2 Department of Pharmaceutical Sciences, College of Pharmacy, Almaarefa University, Riyadh 11597, Saudi Arabia

3 Department of Pharmaceutics, School of Pharmaceutical Education and Research, Jamia Hamdard, New Delhi 110062, India; mdrizwanullah54@gmail.com

4 Genome Biology Laboratory, Department of Biosciences, Jamia Millia Islamia, New Delhi 110025, India; fakhri.khalid@rediffmail.com (K.U.F.); rizvijmi@gmail.com (M.M.A.R.)

* Correspondence: simam@ksu.edu.sa or sarimimam@gmail.com

\begin{abstract}
In the present study, thymoquinone (TQ)-encapsulated chitosan- (CS)-coated poly(D,Llactide-co-glycolide) (PLGA) nanoparticles (NPs) were formulated using the emulsion evaporation method. NPs were optimized by using $3^{3}-\mathrm{QbD}$ approach for improved efficacy against breast cancer. The optimized thymoquinone loaded chitosan coated Poly (D,L-lactide-co-glycolide) nanoparticles (TQ-CS-PLGA-NPs) were successfully characterized by different in vitro and ex vivo experiments as well as evaluated for cytotoxicity in MDA-MB-231 and MCF-7 cell lines. The surface coating of PLGA-NPs was completed by CS coating and there were no significant changes in particle size and entrapment efficiency (EE) observed. The developed TQ-CS-PLGA-NPs showed particle size, polydispersibility index (PDI), and \%EE in the range between 126.03-196.71 nm, 0.118-0.205, and $62.75 \%-92.17 \%$. The high and prolonged TQ release rate was achieved from TQ-PLGA-NPs and TQ-CS-PLGA-NPs. The optimized TQ-CS-PLGA-NPs showed significantly higher mucoadhesion and intestinal permeation compared to uncoated TQ-PLGA-NPs and TQ suspension. Furthermore, TQ-CS-PLGA-NPs showed statistically enhanced antioxidant potential and cytotoxicity against MDA-MB-231 and MCF-7 cells compared to uncoated TQ-PLGA-NPs and pure TQ. On the basis of the above findings, it may be stated that chitosan-coated TQ-PLGA-NPs represent a great potential for breast cancer management.
\end{abstract}

Keywords: thymoquinone; breast cancer; chitosan; PLGA; coating; cytotoxicity

\section{Introduction}

Breast cancer (BC) is the most frequent and deadliest solid tumor among women with over 1.1 million diagnosed cases every year globally. It is a leading cause of cancer deaths with a mortality rate of higher than $1.6 \%$ in women globally [1]. Moreover, $\mathrm{BC}$ comprises more than $10.4 \%$ cases alone among all the cancer incidences in women globally. A dramatic increase in incidences of $\mathrm{BC}$ has been reported over the last three decades, due to complex lifestyle and environmental changes. Since the last few decades, various BC treatment strategies have been used in clinics. Among them, conventional chemotherapy is the most successful to date, but its non-selective delivery, serious adverse effects, and multi-drug resistance limit its application [2].

Thymoquinone (TQ: 2-isopropyl-5-methylbenzo-1,4-quinone), a major active constituent of Nigella sativa, is one of the most potent therapeutic molecules used in the 
treatment of various diseases. At present, TQ is one of the most promising chemotherapeutic drugs used in the treatment of a variety of solid and liquid tumors [3,4]. The reason behind the success of TQ in the treatment of different cancers is the selectivity and therapeutic efficacy against cancer cells and negligible toxicity to normal cells [3]. Despite the promising therapeutic efficacies of TQ, lipophilicity, low aqueous solubility, low oral bioavailability, light and $\mathrm{pH}$ sensitivity limit its clinical translation [5].

The development of TQ-encapsulated nanoparticles could emerge as a novel nano platform to overcome the limitations related to the delivery of TQ. Encapsulation of TQ in nanoparticles could increase its solubility, bioavailability, stability in light and different $\mathrm{pH}$ of biological systems, therapeutic delivery, and targeting ability to the specific target site. Therefore, the development of a biodegradable, biocompatible, and significantly safe and effective nanoparticle-based drug delivery system is an urgent need for successful cancer therapy [5].

Poly(D,L-lactide-co-glycolide) (PLGA) is an FDA-approved biocompatible and biodegradable synthetic polymer extensively used in the delivery of a variety of chemotherapeutic agents for the management of different solid tumors [6-8]. PLGA-nanoparticles (NPs) can enhance aqueous solubility, penetration of drugs from gastrointestinal mucosa, bioavailability, plasma half-life, and therapeutic efficacy of a variety of chemotherapeutic agents. In addition, PLGA-NPs significantly reduce the serious adverse effects by selective targeting of the drug to the target site [8,9]. PLGA produces spherical NPs and negative charge on the surface of NPs, which provides stability to the NPs from hostile $\mathrm{pH}$ of the biological system. Furthermore, it releases the encapsulated drugs slowly from the NPs by polymer hydrolysis. However, oral delivery of drugs through PLGA-NPs is still not very successful due to the lack of mucoadhesiveness [10]. Apart from that, the negatively charged surface of PLGA-NPs can obstruct the interaction with intestinal mucosa, which has a negative charge on the surface that results in limited intestinal uptake and bioavailability of encapsulated drugs [10,11].

Chitosan (CS), a natural, non-toxic, biodegradable, and biocompatible cationic polymer, is an extensively used biomaterial for improved oral delivery of a variety of therapeutic drugs due to the unique physicochemical characteristics such as its mucoadhesiveness as well as intestinal permeability enhancing properties. In addition, it has excellent stability in hostile gastrointestinal fluids $[12,13]$. Surface modification of PLGA-NPs with CS offers various unique advantages such as it provides a positive charge to the NPs, which enhances adhesion of NPs to the intestinal mucosa and also increases the retention on the target site [14]. Therefore, CS coating of PLGA-NPs significantly increases the residence time of NPs at the target site, which leads to enhanced bioavailability of encapsulated drugs, decreases the dose of the drug, reduces dosing frequency, and decreases adverse effects [15].

Therefore, the current study was planned to formulate effective chitosan-coated TQPLGA-NPs. The formulation was optimized by using three factors at three levels of Box-Behnken design (BBD). The optimized TQ-CS-PLGA-NPs were further evaluated for in vitro release, mucoadhesion study, and the results compared with uncoated TQPLGA-NPs. Finally, antioxidant study and anticancer cell line activity (MDA-MB-231 and MCF-7) were performed to analyze the potential TQ-PLGA-NPs and TQ-CS-PLGA-NPs and free TQ.

\section{Materials and Methods}

\subsection{Materials}

Thymoquinone (TQ), chitosan (MW 100,000-300,000), polyvinyl alcohol (PVA, MW 31,000-50,000 Da), TPGS was procured from Sigma-Aldrich, Saint Louis, MO, USA. PLGA (50:50, viscosity 0.8-1.2 dL/g) was provided by Evonik India Pvt Ltd., Mumbai, India, as a gift sample. The experiment was performed with Milli Q water obtained from the laboratory. All other chemicals and reagents used were of AR grade. 


\subsection{Cell Lines}

The cell line study was performed on MDA-MB-231 and MCF-7 breast cell lines. The cells were procured from the National Centre for Cell Science, Pune India. The cells were cultured in streptomycin $(100 \mathrm{mg} / \mathrm{mL})$ with Dulbecco's modified Eagle medium (DMEM), FBS (10\%), penicillin $100 \mathrm{U} \cdot \mathrm{mL}^{-1}$ in a specific condition. The cells were subcultured to obtain $80 \%-90 \%$ growth for the experiments.

\subsection{Reverse-Phase High-Performance Liquid Chromatography (RP-HPLC) Technique}

The RP-HPLC technique was reproduced as per the procedure reported by Gilani et al. [16]. The RP-HPLC system (Waters 2695) connected with a UV detector (Waters 2475 Multi Lambda) was used for the study. The RP-HPLC system consists of a binary pump (model 1525; Milford, CT, USA), and the column used for the study is C18 $(150 \mathrm{~mm} \times 3.9 \mathrm{~mm} \times 5 \mu \mathrm{m})$. The mobile phase composition water: 2-propanol:methanol $(50: 45: 5 \mathrm{v} / \mathrm{v} / \mathrm{v})$ with a flow rate of $1 \mathrm{~mL} / \mathrm{min}$ was used for the study. The mobile phase was degassed and filtered before use. The injection volume was $20 \mu \mathrm{L}$ and the detection of the sample was completed at $255 \mathrm{~nm}$. The data acquisition was carried out using Empower software.

\subsection{Experimental Design}

In the present study, the NPs were optimized by the $3^{3}$-BBD technique to obtain a robust composition of excipients without undergoing trial and error. The software (Design Expert $^{\circledR}$ 12.0; Stat-Ease Inc., Minneapolis, MN, USA) was used to optimize the prepared NPs (i.e., TQ-CS-PLGA-NPs) [17,18]. The three independent factors used for the study were PLGA $\left(X_{1} ; 2 \%-4 \%\right)$, PVA $\left(X_{2} ; 1.5 \%-2.5 \%\right)$, and sonication time $\left(X_{3} ; 2-4 \mathrm{~min}\right)$ as depicted in Table 1. A significant impact of all 3 independent variables was examined on all 3 dependent variables (particle size (PS as $Y_{1}$ in nm), polydispersibility index (PDI; $Y_{2}$ ), and entrapment efficiency $\left(\mathrm{EE} ; Y_{3}\right.$ in \%)). The formulation design showed 15 total experimental compositions with three center points, as depicted in Table 2 . The point prediction method was used to select the optimized TQ-CS-PLGA-NPs on the basis of minimum particle size (PS), PDI, and maximum EE. The statistical analysis was used to assess the independent variables affecting the responses as well as the interaction between the factors.

Table 1. Various independent and dependent variables used in the Box-Behnken design for the preparation of TQ-CS-PLGA-NPs.

\begin{tabular}{ccccc}
\hline Independent Variables & \multicolumn{3}{c}{ Levels Used } & Dependent Variables \\
\hline & Low & Medium & High & \\
\hline$X_{1}=$ PLGA concentration (\%) & 2 & 3 & 4 & $Y_{1}=$ Particle size (nm) \\
$X_{2}=$ PVA concentration $(\%)$ & 1.5 & 2 & 2.5 & $Y_{2}=$ Polydispersity index \\
$X_{3}=$ Sonication time (min) & 2 & 3 & 4 & $Y_{3}=$ Entrapment efficiency (\%) \\
\hline
\end{tabular}

Table 2. Observed Box-Behnken experimental runs of TQ-CS-PLGA-NPs with their actual and predicted experimental values of $Y_{1}, Y_{2}$, and $Y_{3}$.

\begin{tabular}{|c|c|c|c|c|c|c|c|c|c|}
\hline \multirow[t]{3}{*}{ Runs } & \multicolumn{3}{|c|}{$\begin{array}{c}\text { Independent } \\
\text { Variables }\end{array}$} & \multicolumn{6}{|c|}{ Dependent Variables } \\
\hline & \multirow[t]{2}{*}{$X_{1}$} & \multirow[t]{2}{*}{$X_{2}$} & \multirow[t]{2}{*}{$X_{3}$} & \multicolumn{2}{|c|}{$Y_{1}$} & \multicolumn{2}{|c|}{$Y_{2}$} & \multicolumn{2}{|c|}{$Y_{3}$} \\
\hline & & & & Actual & Predicted & Actual & Predicted & Actual & Predicted \\
\hline $\mathrm{F} 1$ & 4 & 2 & 2 & 196.71 & 196.91 & 0.178 & 0.176 & 92.17 & 92.03 \\
\hline $\mathrm{F} 2$ & 3 & 2 & 3 & 156.94 & 156.48 & 0.139 & 0.145 & 78.23 & 78.64 \\
\hline F3 & 4 & 2 & 4 & 174.84 & 175.1 & 0.205 & 0.208 & 79.34 & 79.05 \\
\hline $\mathrm{F} 4$ & 4 & 1.5 & 3 & 192.59 & 192.4 & 0.182 & 0.181 & 84.21 & 84.54 \\
\hline F5 & 3 & 2.5 & 2 & 184.65 & 184.72 & 0.12 & 0.123 & 85.32 & 85.36 \\
\hline F6 & 3 & 2 & 3 & 153.46 & 156.48 & 0.136 & 0.145 & 78.84 & 78.64 \\
\hline
\end{tabular}


Table 2. Cont.

\begin{tabular}{|c|c|c|c|c|c|c|c|c|c|}
\hline \multirow[t]{3}{*}{ Runs } & \multicolumn{3}{|c|}{$\begin{array}{l}\text { Independent } \\
\text { Variables }\end{array}$} & \multicolumn{6}{|c|}{ Dependent Variables } \\
\hline & \multirow[t]{2}{*}{$X_{1}$} & \multirow[t]{2}{*}{$X_{2}$} & \multirow[t]{2}{*}{$X_{3}$} & \multicolumn{2}{|c|}{$Y_{1}$} & \multicolumn{2}{|c|}{$Y_{2}$} & \multicolumn{2}{|c|}{$Y_{3}$} \\
\hline & & & & Actual & Predicted & Actual & Predicted & Actual & Predicted \\
\hline F7 & 4 & 2.5 & 3 & 181.42 & 181.15 & 0.164 & 0.162 & 89.69 & 89.79 \\
\hline F8 & 3 & 1.5 & 2 & 184.42 & 184.41 & 0.157 & 0.158 & 80.68 & 80.49 \\
\hline F9 & 2 & 2 & 4 & 126.03 & 125.83 & 0.147 & 0.148 & 62.75 & 62.89 \\
\hline F10 & 3 & 1.5 & 4 & 164.74 & 164.67 & 0.162 & 0.158 & 69.85 & 69.81 \\
\hline F11 & 3 & 2.5 & 4 & 147.98 & 147.99 & 0.154 & 0.152 & 74.86 & 75.05 \\
\hline F12 & 2 & 2.5 & 3 & 141.19 & 141.38 & 0.118 & 0.118 & 71.27 & 70.94 \\
\hline F13 & 2 & 1.5 & 3 & 146.21 & 146.48 & 0.138 & 0.139 & 66.19 & 66.09 \\
\hline F14 & 3 & 2 & 3 & 157.42 & 156.48 & 0.148 & 0.145 & 78.84 & 78.64 \\
\hline F15 & 2 & 2 & 2 & 160.74 & 160.48 & 0.154 & 0.15 & 70.62 & 70.91 \\
\hline
\end{tabular}

$\mathrm{X}_{1}=$ concentration of poly(D,L-lactide-co-glycolide) (PLGA) (\%); $X_{2}=$ concentration of PVA (\%); $X_{3}=$ sonication time $(\mathrm{min}) ; Y_{1}=$ particle size $(\mathrm{nm}) ; Y_{2}=$ polydispersity index; $Y_{3}=$ entrapment efficiency $(\%)$.

\subsection{Formulation of TQ-CS-PLGA-NPS}

TQ-NPs were formulated by the single-emulsion solvent evaporation technique as per the procedure reported by Abd El Hady et al. [19]. The two different solutions were prepared to formulate TQ-PLGA-NPs. In methylene chloride (organic phase $4 \mathrm{~mL}$ ), TQ (20 mg), and PLGA ( $2 \%-4 \% w / v$, low to high) was dissolved. Separately, the aqueous phase was prepared with the addition of PVA $(1.5 \%-2.5 \% w / v$, low to high), and TPGS $(0.25 \% w / v)$. The organic solution was transferred into the aqueous solution and sonicated (Hielscher, Ultrasound UP-50H, Teltow, Germany) for 2-4 min (low to high) to obtain a primary emulsion. The organic phase was evaporated with continuous magnetic stirring (Heidolph, IL, USA). The prepared TQ-PLGA-NPs were separated by centrifugation at $10,000 \mathrm{rpm}$ for $1 \mathrm{~h}$ followed by washing with water.

Chitosan-coated PLGA nanoparticles were prepared by adding CS $(0.1 \% w / v)$ in acetic acid $(2 \% v / v)$ solution to TQ-PLGA-NPs and then incubated for $2 \mathrm{~h}$. Finally, the prepared TQ-CS-PLGA-NPs were reconstituted by centrifugation (Sigma 3K30, Osterode am Harz, Germany) at 10,000 rpm for $1 \mathrm{~h}$ and washed three times with Milli $\mathrm{Q}$ water. In the end, NPs were lyophilized by adding mannitol $(2.5 \% w / v)$ as a cryoprotectant for further characterization.

\subsection{Characterization}

\subsubsection{Particle Characterization}

The prepared TQ-PLGA-NPs and TQ-CS-PLGA-NPs were characterized for PS, PDI, and zeta potential (ZP). The diluted samples (100-fold) of NPs were measured in a zeta sizer. ZP of optimized NPs was assessed to determine the charge on NPs' surface [20]. The surface morphology of TQ-PLGA-NPs and TQ-CS-PLGA-NPs was evaluated on TEM (TEM-2100, JEO, Tokyo, Japan) at $160 \mathrm{kV}$ voltage [21]. The samples were coated with phosphotungstic acid and visualized under the microscope at high resolution. The micrographs were captured and visualized with the help of image viewing software.

\subsubsection{Entrapment Efficiency}

The prepared formulations were evaluated for encapsulation efficiency by estimating the free TQ in the supernatant. The prepared formulations were centrifuged at 10,000 rpm and the supernatant was collected. The unentrapped TQ was diluted further to quantify TQ by UV spectrophotometer at $255 \mathrm{~nm}$. The blank NPs supernatant was used to evaluate the samples [19]. Then, \%EE was calculated with the use of the below equation:

$$
\% \mathrm{EE}=\frac{\text { Amount of } \mathrm{TQ}-\text { Amount of free } \mathrm{TQ}}{\text { Amount of } \mathrm{TQ}} \times 100
$$




\subsection{In Vitro Gastrointestinal Stability Study}

The prepared optimized formulation (TQ-CS-PLGA-NPs) was evaluated for gastrointestinal stability as per the published procedure [22,23]. The stability was assessed in simulated intestinal fluid (SIF) and gastric fluid (SGF). TQ-CS-PLGA-NPs $(0.1 \mathrm{~mL})$ were withdrawn and diluted up to $5 \mathrm{~mL}$ (1 in 50) in SIF and SGF and incubated at $37^{\circ} \mathrm{C}$. After specific time intervals $(0,2,4,8,12 \mathrm{~h})$, the sample was evaluated for PS, PDI, and EE.

\subsection{Colloidal Stability}

The colloidal stability of optimized TQ-CS-PLGA-NPs was conducted as per the previously published method with a minor modification [23]. The freeze-dried TQ-CSPLGA-NPs were stored at $4{ }^{\circ} \mathrm{C}$ for 90 days (three months). TQ-CS-PLGA-NPs were taken at the time points of 0,1 , and 3 months, and dispersed in phosphate buffer saline $\mathrm{pH} 7.4$ for determination of PS, PDI, and \%EE.

\subsection{TQ Release Study}

The comparative TQ release study was conducted between TQ-PLGA-NPs, TQ-CSPLGA-NPs, and TQ suspension (control) in release medium SIF (500 mL, pH 6.8) at 37 ${ }^{\circ} \mathrm{C}$. Weighed content of prepared NPs ( $\sim 5 \mathrm{mg}$ of TQ) was placed in the dialysis bag (MW $12,000 \mathrm{D}$ ) and dipped into release medium with stirring speed of $100 \mathrm{rpm}$. At specific time points, the released content $(5 \mathrm{~mL})$ was withdrawn and replaced with the same volume. The collected samples were filtered, diluted, and analyzed to quantify TQ content using a UV spectrophotometer at $255 \mathrm{~nm}$. Further, the released data fitted into various kinetic models to analyze the mechanism of TQ release from the NPs [24].

\subsection{Mucoadhesion Study}

TQ-PLGA-NPs, TQ-CS-PLGA-NPs, and TQ suspension were evaluated for mucoadhesion study to check the adsorption of mucin on the NPs [25]. The mucin solution $(1 \mathrm{mg} / \mathrm{mL})$ was prepared and mixed with the prepared formulations in 1:1 ratio. The mixture was incubated at $37^{\circ} \mathrm{C}$ for $2 \mathrm{~h}$ and then centrifuged at $13,000 \mathrm{rpm}$ for $60 \mathrm{~min}$. The supernatant was taken, diluted appropriately, and analyzed spectrophotometrically at $258 \mathrm{~nm}$ to calculate the free mucin content. The formula used to calculate is given below [26].

$$
\text { Mucoadhesive efficiency }=\frac{\mathrm{C}_{0}-\mathrm{C}_{\mathrm{f}}}{\mathrm{C}_{0}} \times 100
$$

where $\mathrm{C}_{0}=$ initial mucin content and $\mathrm{C}_{\mathrm{f}}=$ free mucin content.

\subsection{Antioxidant Activity}

The activity performed for TQ-PLGA-NPs, TQ-CS-PLGA-NPs, and TQ suspension to check the antioxidant activity was the reported procedure with a slight modification [27]. The stock solution $(10 \mathrm{mg} / \mathrm{mL})$ was prepared for all three samples in ethanol and further diluted to make $25-300 \mu \mathrm{g} / \mathrm{mL}$ concentration range. All the samples $(500 \mu \mathrm{L})$ were taken and transferred to DPPH solution $(0.02 \%$ in ethanol). The samples were shaken for complete reaction and placed in the dark at $25^{\circ} \mathrm{C}$ for $1 \mathrm{~h}$. The reaction took place between violet color DPPH and antioxidants. The violet color of the solution turns colorless after the completion of the reaction. Similarly, this experiment was repeated for placebo NPs. The samples were examined spectrophotometrically at $517 \mathrm{~nm}$, and calculation was completed using the formula:

$$
\text { Radical Scavenging }(\%)=\frac{\text { Absorbance of control }- \text { Absorbance of test }}{\text { Absorbance of control }} \times 100
$$

\subsection{Cell Viability Assay}

MTT assay of TQ-PLGA-NPs, TQ-CS-PLGA-NPs, and TQ suspension was performed to check the cell viability [28]. This test works on the mechanism of the formation of 
yellow tetrazolium salt to insoluble purple formazan crystals [29]. Both MDA-MB-231 and MCF-7 cells were seeded $24 \mathrm{~h}$ before the study. The cell counts $1 \times 10^{5} /$ well were taken for the study, and a different concentration of each sample was incubated for $24 \mathrm{~h}$ and $48 \mathrm{~h}$, respectively. After that, the cells were incubated with MTT (20 $\mu \mathrm{L}, 5 \mathrm{mg} / \mathrm{mL}$ in PBS) in fresh medium for $4 \mathrm{~h}$ under $\mathrm{CO}_{2}$ incubator. The formed formazan crystal was solubilized in DMSO $(150 \mu \mathrm{L} /$ well). The absorbance was noted at $570 \mathrm{~nm}$ on a microplate reader.

\subsection{Intestinal Permeation Study}

The permeation experiment of TQ-PLGA-NPs, TQ-CS-PLGA-NPs, and TQ suspension was conducted to determine the amount of drug permeated at specific times. The study was performed on the goat intestine by the reported procedure with slight modification [30,31]. The fresh goat intestine was collected from the local slaughterhouse at an abattoir in a sterile beaker and washed with Kreb's solution to remove the food residues. The formulations ( $\sim 5 \mathrm{mg}$ of TQ) were carefully placed in the intestinal sac, and both ends were ligated tightly. The samples were placed in a beaker containing Kreb's solution (250 mL) and regularly oxygenated with $95 \%$ oxygen using an aerator. The released content $(2 \mathrm{~mL})$ was taken at a specific time point and replaced with the same volume. The samples were filtered, diluted, and quantified by using the RP-HPLC technique at $255 \mathrm{~nm}$ [16]. The permeation flux and apparent permeability coefficient $\left(\mathrm{APC} ; \mathrm{P}_{\mathrm{app}}\right.$ ) were determined for the formulations by the following equation:

$$
\mathrm{APC}=\frac{\text { Permeation flux }}{\text { Surface area } \times \text { Initial TQ content }} \mathrm{cm} / \mathrm{min}
$$

\subsection{Statistical Analysis}

Experiments were conducted 3 times, and their findings were represented as average \pm SD. The statistical analysis was performed with GraphPad prism (version 7). Furthermore, the data were analyzed statistically using ANOVA and Tukey's test with the help of GraphPad Prism, version 7. The data were considered statistically significant when $p<0.05$.

\section{Results and Discussion}

\subsection{Optimization}

The developed TQ-CS-PLGA-NPs were statistically optimized with $3^{3}$-BBD. The impact of independent variables $\left(X_{1}, X_{2}\right.$, and $\left.X_{3}\right)$ on the dependent variables $\left(Y_{1}, Y_{2}\right.$, and $Y_{3}$ ) was evaluated by 3D response surface plot (Figure 1 ), and contour plot (Figure 2$)$. The polynomial equations obtained from the software were used to assess the individual, as well as the combined, impact of all three independent variables. The quadratic model is commonly used for studying the major impact because this model uses the selected variables individually, as well as combinedly.

The independent variables PLGA $\left(\%, X_{1}\right)$; PVA $\left(\%, X_{2}\right)$ and ST $\left(\%, X_{3}\right)$ were taken at three levels (low $(-1)$, medium $(0)$, and high $(+1)$ ) to optimize TQ-CS-PLGA-NPs as shown in Table 1 . The concentration ranges taken to develop TQ-CS-PLGA-NPs were PLGA $\left(X_{1}\right)$ as $2 \%(-1)$ to $4 \%(+1)$, PVA $\left(X_{2}\right)$ as $1.25 \%(-1)$ to $2.5 \%(+1)$ and ST $2 \mathrm{~min}(-1)$ to $4 \mathrm{~min}$ $(+1)$. The BBD represented 15 formulations with three center points to analyze any errors in the results of the same three compositions. The minimal PS $\left(Y_{1}\right)$ was observed to be $126.03 \mathrm{~nm}$ (F9), and the maximal PS was observed to be $196.71 \mathrm{~nm}(\mathrm{~F} 1)$. The PDI (Y $\left.{ }_{2}\right)$ was obtained in the range of $0.118(\mathrm{~F} 12)$ to $0.205(\mathrm{~F} 3)$, and the $\% \mathrm{EE}\left(\mathrm{Y}_{3}\right)$ was obtained in the range $62.75 \%(\mathrm{~F} 9)$ to $92.17 \%(\mathrm{~F} 1)$. The results obtained from the experiment, i.e., actual value, were observed to be much closer to the predicted value, as represented in Table 2.

\subsubsection{Effect of PLGA $\left(X_{1}\right)$, PVA $\left(X_{2}\right)$, and ST $\left(X_{3}\right)$ on PS $\left(Y_{1}\right)$}

The polynomial equation indicating the relationship between the factors on $\mathrm{PS}\left(Y_{1}\right)$ is presented as follows:

Particle size $\left(Y_{1}\right)=+158.38+21.42 X_{1}-4.09 X_{2}-14.12 X_{3}-1.54 X_{1} X_{2}+3.21 X_{1} X_{3}-4.25 X_{2} X_{3}+1.50 X_{1}^{2}+7.37 X_{2}^{2}+6.60 X_{3}^{2}$ 
The impact of all the three independent variables $\left(X_{1}, X_{2}\right.$, and $\left.X_{3}\right)$ has been illustrated in the 3D plot (Figure 1A) and contour plot (Figure 2A). As per the polynomial equation and Figures $1 \mathrm{~A}$ and $2 \mathrm{~A}$, a considerable impact of each independent variable on PS $\left(Y_{1}\right)$ can be observed. Gradual increment in the PS was observed with the increase in PLGA $\left(X_{1}\right)$ concentration. Higher polymer concentration increases the viscosity of the formulation, which leads to the enhancement of PS [32]. In addition, high viscosity decreases the diffusion of the drug from NPs, which is another factor for enhanced PS [33]. The variable PVA $\left(X_{2}\right)$ showed a strong negative impact on the PS. Increment in the concentration of PVA from $1.5 \%$ to $2.5 \%$ significantly $(p<0.05)$ decreased the PS. PVA is a surfactant and stabilizer that helps in the emulsification of polymer in the aqueous phase and prevents aggregation of NPs [34]. Another probable elucidation for such reduction in the PS might occur from ST $\left(X_{3}\right)$, which has a direct and strong negative impact on PS, which is an essential step for reduction in PS during the development of TQ-CS-PLGA-NPs [35].

(A)
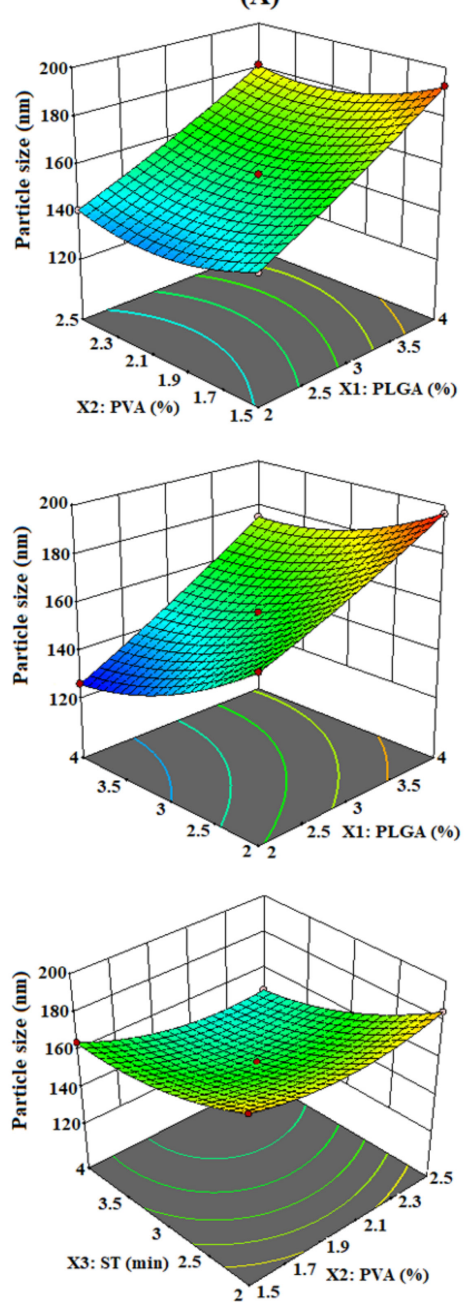

(B)
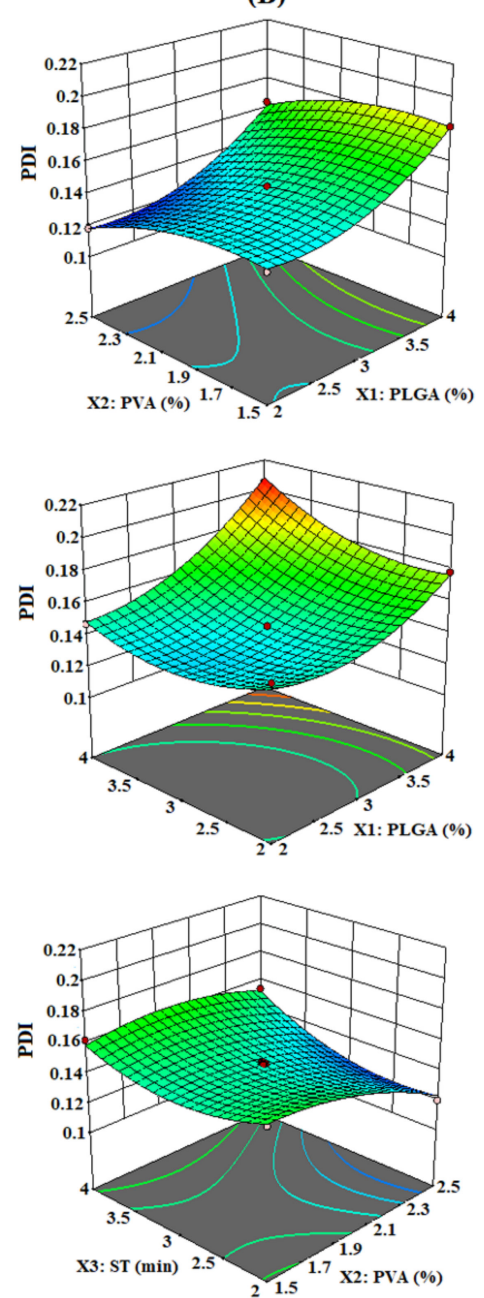

(C)
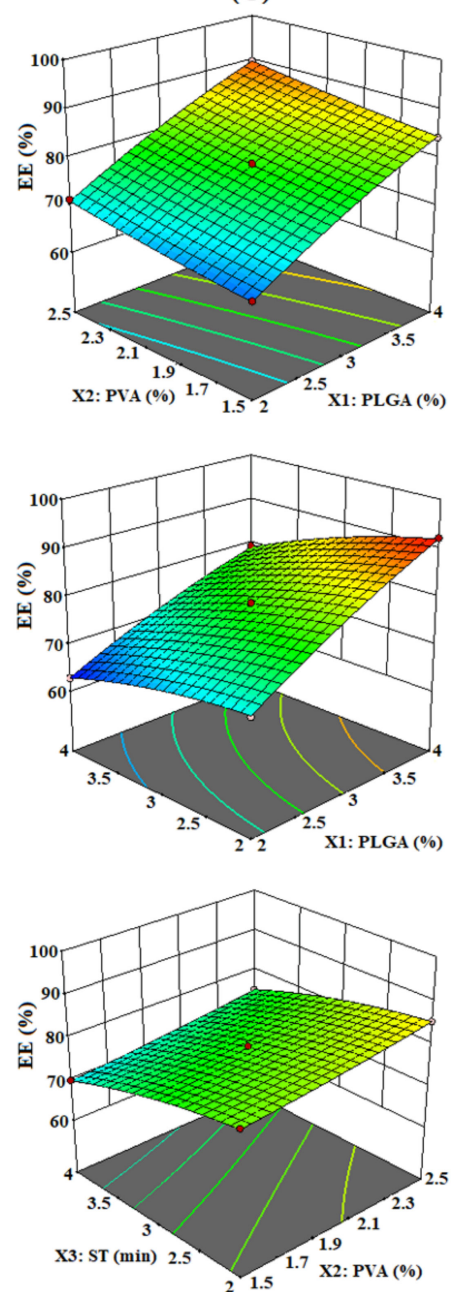

Figure 1. Response surface plots showing the influence of PLGA $\left(X_{1}\right)$, PVA $\left(X_{2}\right)$, and ST $\left(X_{3}\right)$ on response parameters: (A) PS $\left(Y_{1}\right),($ B $)$ PDI $\left(Y_{2}\right)$, and $(\mathbf{C})$. EE $\left(Y_{3}\right)$ of TQ-CS-PLGA-NPs.

\subsubsection{Effect of PLGA $\left(X_{1}\right)$, PVA $\left(X_{2}\right)$, and ST $\left(X_{3}\right)$ on PDI $\left(Y_{2}\right)$}

The polynomial equation indicating the relationship between the factors on PDI $\left(Y_{2}\right)$ is presented as follows:

Polydispersity index $\left(Y_{2}\right)=+0.145+0.0215 X_{1}-0.0104 X_{2}+0.0074 X_{3}+0.0005 X_{1} X_{2}+0.0085 X_{1} X_{3}$ $+0.0073 X_{2} X_{3}+0.0141 X_{1}^{2}-0.0086 X_{2}^{2}+0.0119 X_{3}^{2}$ 
The impact of all the three independent variables $\left(X_{1}, X_{2}\right.$, and $\left.X_{3}\right)$ has been illustrated in the 3D plot (Figure 1B) and contour plot (Figure 2B). As per the polynomial equation and Figures $1 \mathrm{~B}$ and $2 \mathrm{~B}$, a considerable impact of each independent variable on PDI $\left(Y_{2}\right)$ was observed. As the concentration of PLGA $\left(X_{1}\right)$ increased, PDI also increased insignificantly. In other words, a very little positive impact was noticed with an increment in PLGA concentration. Moreover, PVA $\left(\mathrm{X}_{2}\right)$ showed a strong negative impact on the PDI. The surfactants decreased the interfacial tension between the aqueous and organic phase and led to the development of uniform primary emulsion during the development of CS-PLGANPs [36]. The third variable, ST $\left(X_{3}\right)$, is further responsible for a significant increment in the PDI.

(A)
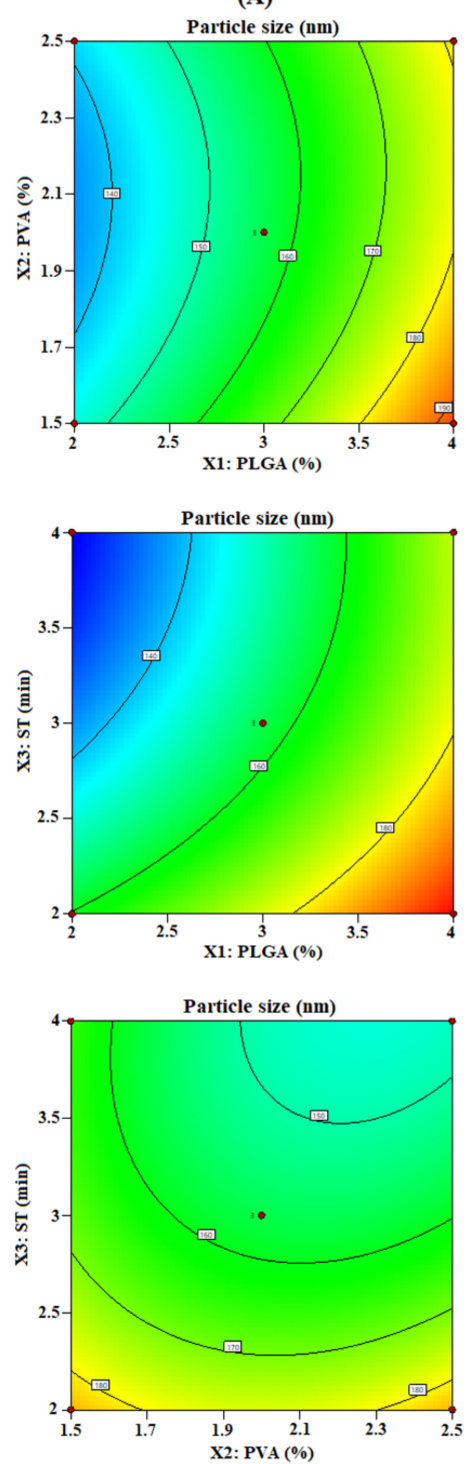

(B)
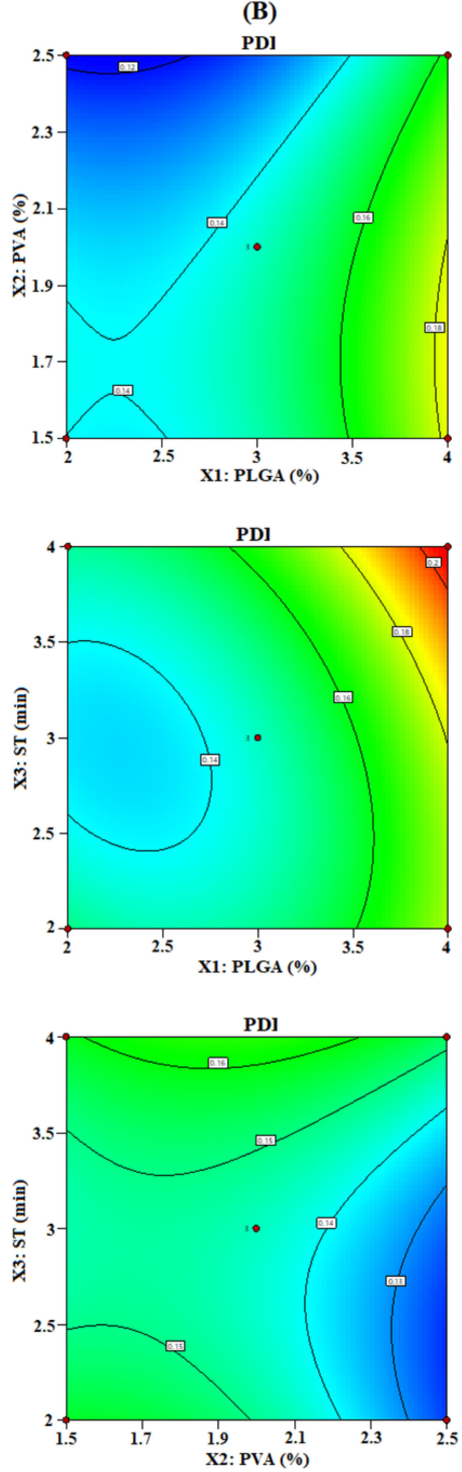

(C)
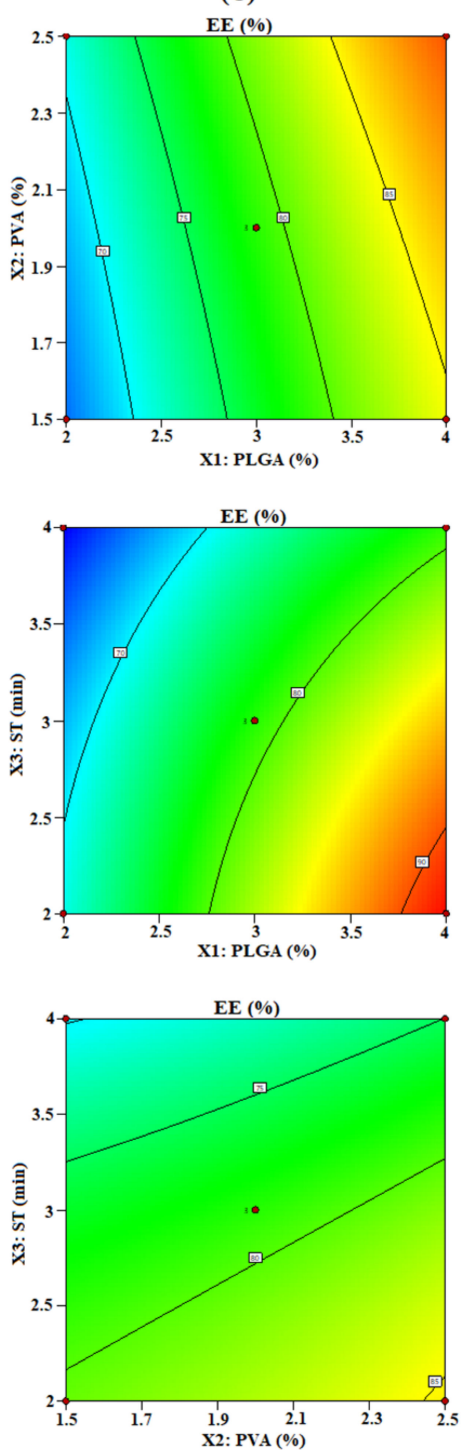

Figure 2. Contour response surface plots showing the influence of PLGA $\left(X_{1}\right)$, PVA $\left(X_{2}\right)$, and ST $\left(X_{3}\right)$ on response parameters: (A) PS $\left(Y_{1}\right)$, (B) PDI $\left(Y_{2}\right)$, and $(\mathbf{C})$ EE $\left(Y_{3}\right)$ of TQ-CS-PLGA-NPs.

\subsubsection{Effect of PLGA $\left(X_{1}\right)$, PVA $\left(X_{2}\right)$, and ST $\left(X_{3}\right)$ on EE $\left(Y_{3}\right)$}

The polynomial equation indicating the relationship between the factors on $\% E E\left(Y_{3}\right)$ is presented as follows:

Entrapment efficiency $\left(Y_{3}\right)=+79.46+9.32 X_{1}+2.53 X_{2}-5.25 X_{3}+0.1 X_{1} X_{2}-1.24 X_{1} X_{3}+0.0925 X_{2} X_{3}$ $-1.13 X_{1}^{2}+0.3304 X_{2}^{2}-1.29 X_{3}^{2}$ 
The impact of all the three independent variables $\left(X_{1}, X_{2}\right.$, and $\left.X_{3}\right)$ has been illustrated in the 3D plot (Figure 1C) and contour plot (Figure 2C). As per the polynomial equation and Figures $1 \mathrm{C}$ and $2 \mathrm{C}$, a considerable impact of each independent variable on PDI $\left(Y_{2}\right)$ was observed. Gradual increment in the \%EE was observed with the increase in PLGA $\left(X_{1}\right)$ concentration. The impact of a polymer depended on the miscibility of the drug in the organic phase as well as the polymer-drug interaction. Furthermore, the maximum solubility of drugs in the polymer solution is due to its better emulsification properties $[20,36]$. Similarly, an increment in the PVA $\left(X_{2}\right)$ concentration gradually improved the \%EE. The concentration of PVA concentration led to an increase in the tendency of the drug to become entrapped in the polymeric matrix, which resulted in improved \%EE [37,38]. Furthermore, an increase in ST $\left(X_{3}\right)$ decreased \%EE significantly due to the reduction in PS.

\subsubsection{Optimization by Point Prediction}

The optimized TQ-CS-PLGA-NPs were selected on the criteria of small PS, PDI, and high EE among 15 compositions, upon "trading off" different responses $\left(Y_{1}, Y_{2}\right.$, and $\left.Y_{3}\right)$ using the numerical desirability function. As per our criteria of low particle size, PDI, and high encapsulation efficiency, the selected optimized formulation has shown a desirability value closer to one and this indicates that the method is strong (Table 3). The ideal desirability range exists between 0 and 1 . A value closer to zero means the method is not strong and a value closer to one means the method is strong [39]. Minimization of the particle is desired for the delivery systems because of the higher surface area available for dissolution and drug absorption. There are many pieces of literature that have reported a significant increase in solubility and dissolution with reduced particle size. According to the Noyes-Whitney equation, the reduction in particle size leads to a significant increase in the dissolution rate of the drug, which in turn can lead to substantial increases in the bioavailability [40]. The optimized formulation composition (TQ-CS-PLGA-NPs) prepared with PLGA $\left(X_{1} ; 3 \%\right)$, PVA $\left(X_{2} ; 2 \%\right)$, and ST $\left(X_{3} ; 3 \mathrm{~min}\right)$ exhibited the particle size of 152.36 $\pm 5.74 \mathrm{~nm}$, PDI of $0.133 \pm 0.014$, and $\mathrm{EE}$ of $77.56 \% \pm 5.48 \%$, respectively. It was further used for in vitro characterization and cell line study. The software examined an analysis of variance (ANOVA) for all three responses $\left(Y_{1}, Y_{2}\right.$, and $\left.Y_{3}\right)$, and the obtained data indicated that the quadratic model was well fitted (Table 3 ). Figure 3 represents the quantitative comparison of the responses of the experimental values with the predicted values.

Table 3. Summary of the regression analysis for responses $Y_{1}, Y_{2}$, and $Y_{3}$ for fitting data to different models.

\begin{tabular}{cccccc}
\hline Model & $\boldsymbol{R}^{\mathbf{2}}$ & Adjusted $\boldsymbol{R}^{\mathbf{2}}$ & Predicted $\boldsymbol{R}^{\mathbf{2}}$ & SD & Desirability \\
\hline Response $\left(Y_{1}\right)$ & & & & & 0.987 \\
Linear & 0.9215 & 0.9001 & 0.8666 & 6.47 & \\
2F1 & 0.9425 & 0.8993 & 0.8393 & 6.49 & \\
Quadratic & 0.9999 & 0.9998 & 0.9988 & 0.2965 & \\
Response $\left(Y_{2}\right)$ & & & & & \\
Linear & 0.7002 & 0.6184 & 0.3938 & 0.0139 & 0.932 \\
2F1 & 0.7703 & 0.5980 & 0.4724 & 0.0143 & \\
Quadratic & 0.9917 & 0.9767 & 0.8671 & 0.0034 & \\
Response $\left(Y_{3}\right)$ & & & & & 0.973 \\
Linear & 0.9817 & 0.9767 & 0.9649 & 1.28 & \\
2F1 & 0.9881 & 0.9791 & 0.9532 & 1.21 & \\
Quadratic & 0.9992 & 0.9978 & 0.9912 & 0.39 & \\
\hline
\end{tabular}

$\overline{Y_{1}}=$ particle size $(\mathrm{nm}) ; Y_{2}=$ polydispersity index; $Y_{3}=$ entrapment efficiency (\%); $R^{2}=$ coefficient of correlation. 


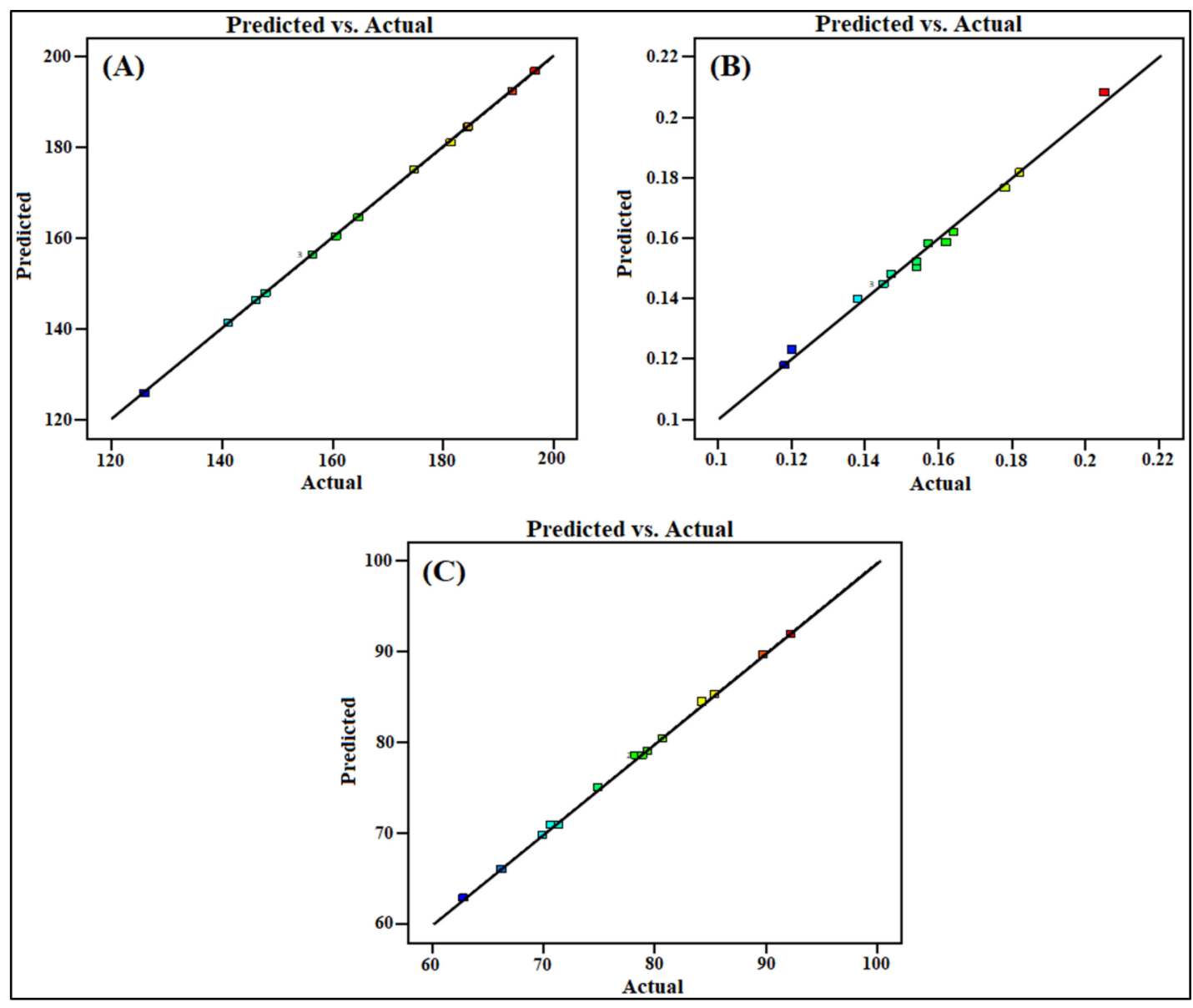

Figure 3. Actual and predicted graph showing linear correlation (A) PS, (B) PDI, (C) EE.

\subsection{Characterization}

\subsubsection{Particle Characterization}

The PS, PDI, and ZP of the optimized TQ-CS-PLGA-NPs were observed to be $152.36 \pm 5.74 \mathrm{~nm}$, $0.133 \pm 0.014$, and $+12.24 \pm 2.32 \mathrm{mV}$, respectively (Figure 4A,B), while uncoated TQ-PLGANPs showed the PS of $141.64 \pm 6.56 \mathrm{~nm}$, PDI of $0.142 \pm 0.012$, and ZP of $-16.42 \pm 3.21 \mathrm{mV}$, respectively. The small PS and PDI of NPs are two of the crucial properties for improved oral delivery. The low PDI indicates the remarkable homogeneity of NPs. An insignificant increase in PS was noticed while developing TQ-CS-PLGA-NPs due to the CS coating. Furthermore, the CS coating leads to positive ZP from the negative ZP because of the cationic nature of CS, which was used as a coating agent to provide cohesiveness to the NPs (Figure 4B). Coating of NPs with CS is a well-established technique to improve oral delivery of drugs [41]. TEM also confirmed that the PS of uncoated PLGA-NPs is found to be smaller than TQ-CS-PLGA-NPs (Figure 4C,D). 

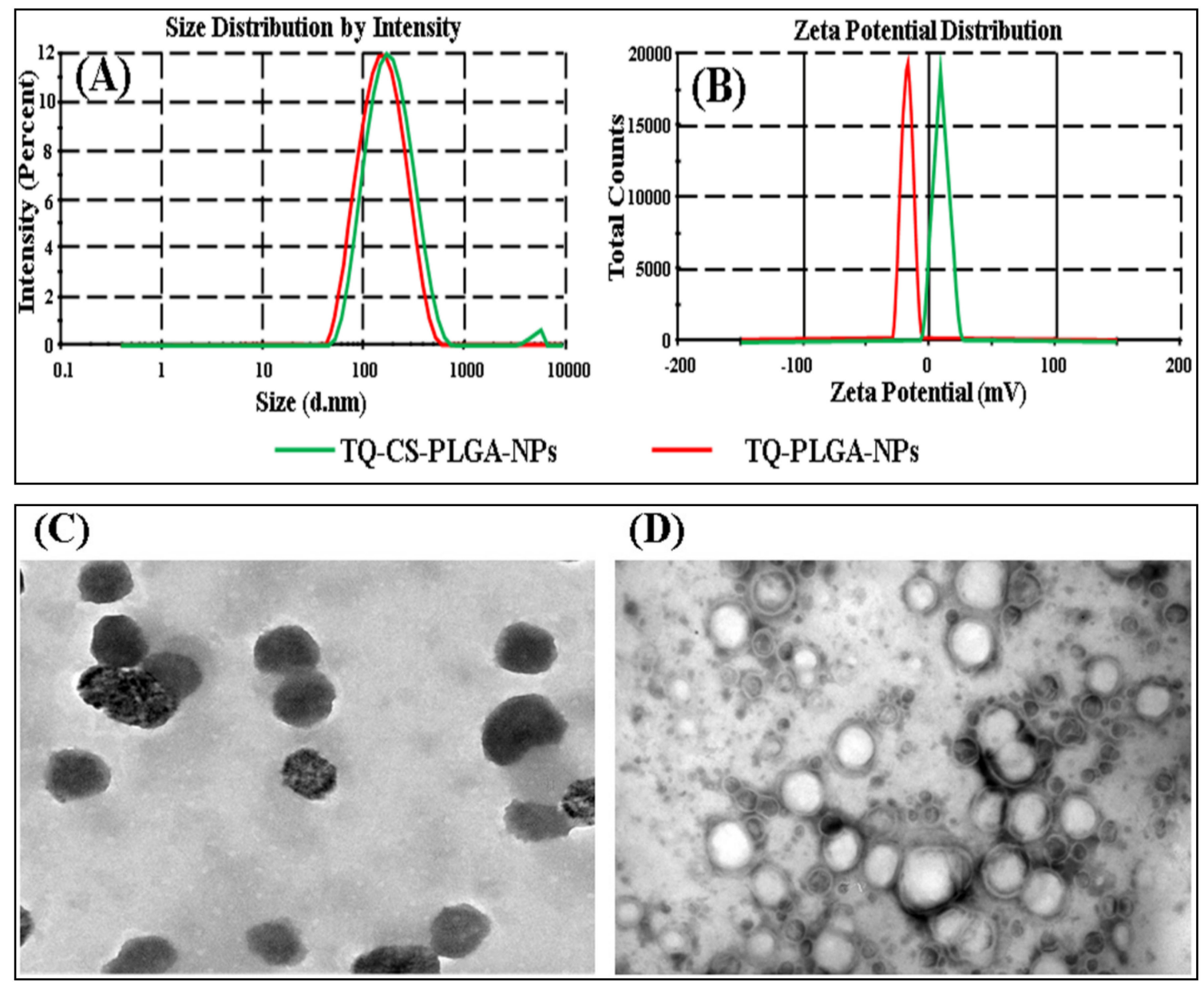

Figure 4. (A,B). Image showing (A) particle size and particle size distribution, (B) zeta potential of optimized TQ-CS-PLGANPs and TQ-PLGA-NPs. (C,D). TEM analysis of (C) optimized TQ-PLGA-NPs, and (D) TQ-CS-PLGA-NPs.

\subsubsection{Entrapment Efficiency (\%EE)}

TQ-CS-PLGA-NPs showed significantly higher \%EE compared to uncoated TQ-PLGANPs due to coating with CS. The optimized TQ-CS-PLGA-NPs and uncoated TQ-PLGANPs showed an encapsulation efficiency of $77.56 \% \pm 5.48 \%$ and $70.78 \% \pm 62 \%$, respectively. An acceptable \%EE is due to the typical polymeric matrix of NPs. Coating with CS forms a layer around the NPs and inhibits the diffusion of TQ from the CS-PLGA-NPs.

\subsection{In Vitro Gastrointestinal Stability Study}

The potential impact of SGF and SIF on the stability of TQ-CS-PLGA-NPs is depicted in Figure 5A,B. The results of the stability study of TQ-CS-PLGA-NPs in SIF demonstrated excellent stability with insignificant $(p>0.05)$ fluctuations in PS, PDI, and \%EE (Figure 5A). However, slightly greater changes in PS, PDI, and \%EE were observed in SGF after $12 \mathrm{~h}$ (Figure 5B). In CS-PLGA-NPs, TQ could be continuously released or accumulated in the intestine region of gastrointestinal tract, which might lead to an increase in epithelial permeability [42]. 


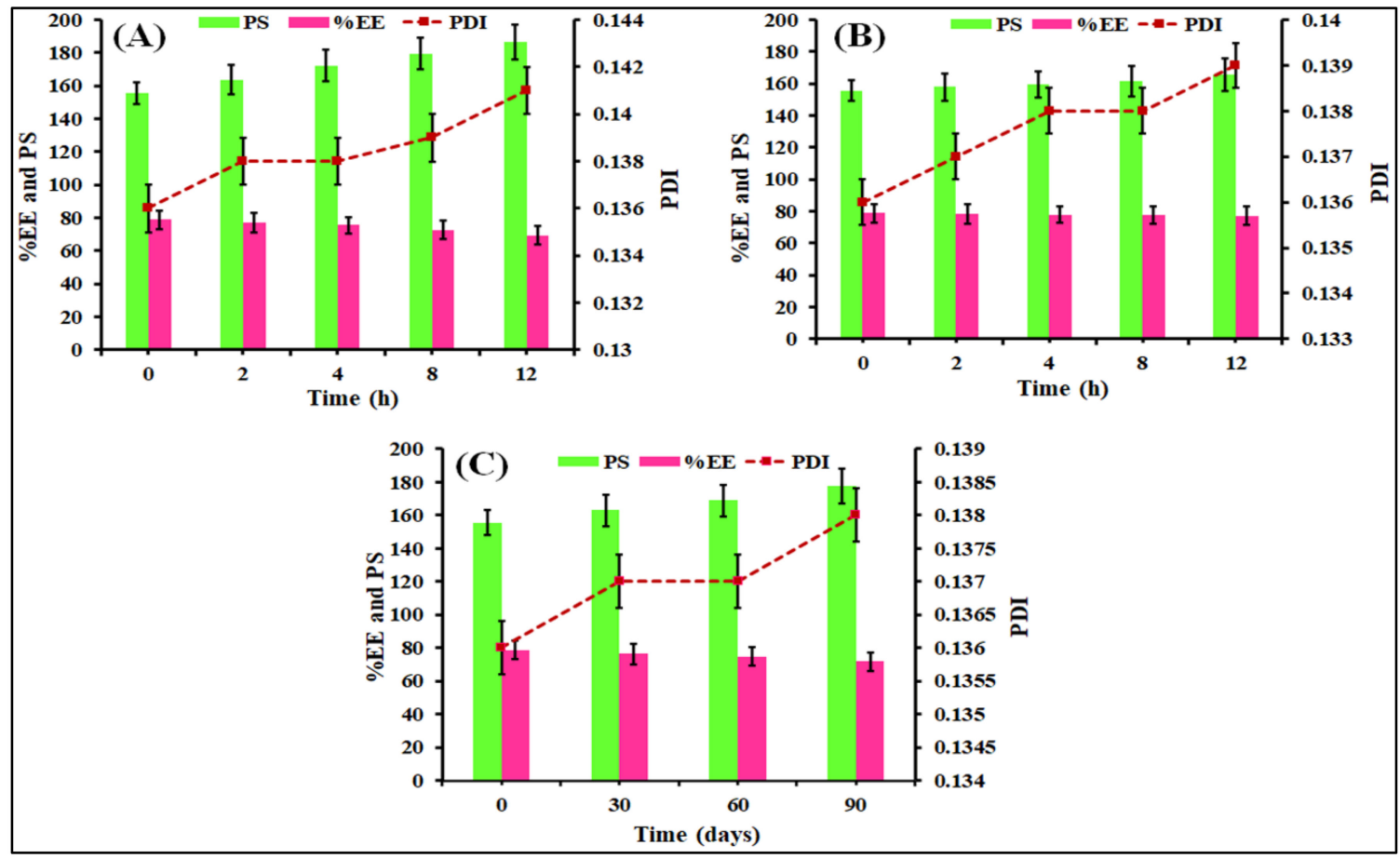

Figure 5. (A-C). Bar graphs showing (A) in vitro gastrointestinal stability study of TQ-CS-PLGA-NPs in SGF, (B) SIF, (C) colloidal stability of TQ-CS-PLGA-NPs. Results are expressed as percentage mean \pm SD $(n=3)$.

\subsection{Colloidal Stability}

After 3 months of storage at $4{ }^{\circ} \mathrm{C}$, the visual clarity and phase separation of TQ-CSPLGA-NPs did not change significantly. The PS, PDI, and EE of TQ-CS-PLGA-NPs are depicted in Figure 5C. The only insignificant increases in PS and PDI were increases from $152.36 \pm 5.74 \mathrm{~nm}$ to $177.84 \pm 10.96 \mathrm{~nm}$ and $0.133 \pm 0.014$ to $0.138 \pm 0.029$, respectively, while the \%EE was still higher than $70 \%$ and was still in an acceptable range. These results indicate that the TQ-CS-PLGA-NPs are capable of maintaining good physical stability at $4{ }^{\circ} \mathrm{C}$ for 3 months.

\subsection{TQ Release Study}

The release profiles of TQ from different formulations are depicted in Figure 6A. Both of the NPs, i.e., TQ-CS-PLGA-NPs, as well as TQ-PLGA-NPs, revealed a biphasic release. Significantly rapid release in $4 \mathrm{~h}$ after that, a sustained TQ release up to $24 \mathrm{~h}$ were observed. The rapid TQ release in the initial $4 \mathrm{~h}$ could be because of the faster dissolution of TQ adsorbed on the NPs' surface [43]. The sustained release after $4 \mathrm{~h}$ to $24 \mathrm{~h}$ was due to the TQ encapsulated in the inner core of the polymeric matrix, which was released slowly by slow diffusion. Furthermore, TQ-CS-PLGA-NPs showed a much-delayed TQ release in comparison with uncoated TQ-PLGA-NPs due to the coating of NPs with CS, possibly because of the protection of the drug from desorption and diffusion [44]. The release of TQ from the TQ suspension was found to be only $27.345 \% \pm 5.56 \%$ after $24 \mathrm{~h}$ of study. This can be explained by the fact that TQ is a water-insoluble drug and its dissolution is limited due to poor solubility [26]. The nanoparticulate delivery systems have reported the enhanced solubility and dissolution of poorly soluble drugs [5]. The release study was performed in identical conditions and due to the poor solubility of $T Q$, its release was limited.

The mechanism of TQ release was analyzed by fitting the data into the different release kinetic models, and different graphical representations are depicted in Figure 6B. The Korsmeyer-Peppas model showed the highest correlation coefficient $\left(R^{2}=0.9605\right)$. Therefore, the Korsmeyer-Peppas kinetic model was considered as the best-fitted model to explain the kinetics of TQ release from CS-PLGA-NPs. Moreover, the exponent " $n$ " 
of release mechanism from the Korsmeyer-Peppas kinetic model was calculated and the value was found 0.282 , which demonstrates the Fickian diffusion mechanism from CS-PLGA-NPs.

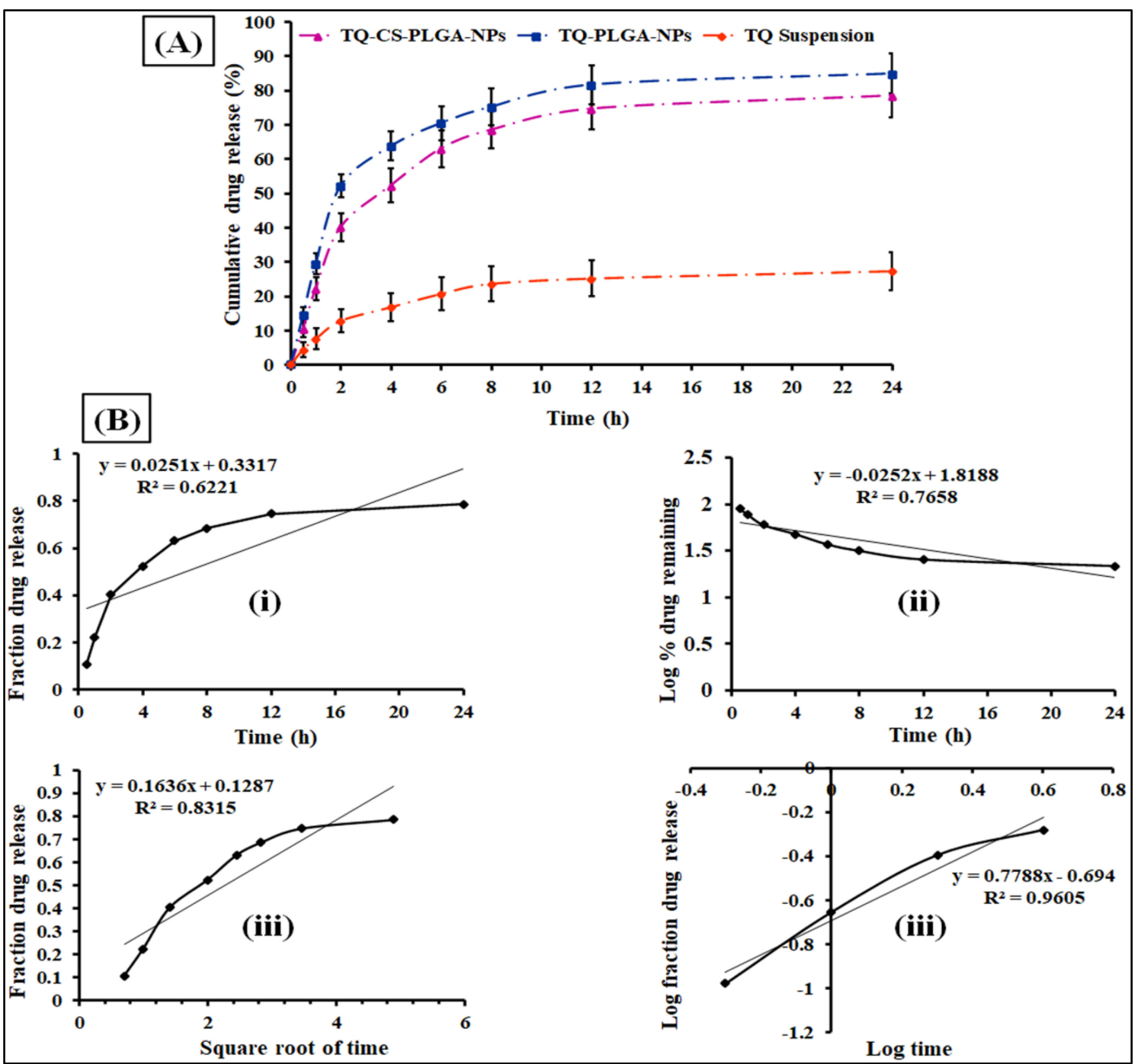

Figure 6. (A) Comparative in vitro release profiles of TQ-PLGA-NPs and TQ-CS-PLGA-NPs. Results are expressed as percentage mean $\pm \mathrm{SD}(n=3)$. (B) In vitro release kinetics model to evaluate the mechanism of drug release from TQ-CS-PLGA-NPs.

\subsection{Mucoadhesion Study}

As expected, TQ-CS-PLGS-NPs revealed the highest mucoadhesive efficiency $(62.58 \% \pm 2.42 \%)$ compared to TQ-PLGA-NPs $(18.74 \% \pm 3.28 \%)$ and TQ suspension $(12.64 \% \pm 2.36 \%)$. The coating of NPs with CS provided a significantly higher binding efficiency to mucin because of the electrostatic interactions between the positive charged CS and negatively charged mucin. Furthermore, hydrogen bonding as well as hydrophobic interactions between CS and mucin are also responsible for improved binding efficiency [45]. The higher mucoadhesive nature of NPs also proved a long gastrointestinal residence time.

\subsection{Antioxidant Activity}

DPPH is utilized to assess the antioxidant potential of a variety of drugs and drug delivery systems [46]. The DPPH changes the color to violet when it reacts with proton donor groups. Figure 7 represents the comparative antioxidant activity of TQ-CS-PLGA-NPs, 
TQ-PLGA-NPs, and pure TQ. The antioxidant potential of all the samples is directly dependent upon the TQ concentration. As the concentration of $T Q$ increases, the antioxidant potential of TQ-CS-PLGA-NPs, TQ-PLGA-NPs, and pure TQ also increases statistically. TQ-CS-PLGA-NPs showed a maximum activity of $96.24 \% \pm 6.78 \%$, while TQ-PLGA-NPs and pure TQ depicted $81.58 \% \pm 5.78 \%$ and $69.26 \% \pm 4.84 \%$, respectively. As per the observation, TQ-CS-PLGA-NPs represented statistically $(p<0.05)$ elevated antioxidant activity in comparison to both uncoated TQ-PLGA-NPs and pure TQ. However, uncoated TQ-PLGA-NPs also showed excellent antioxidant activity compared to pure TQ. The higher antioxidant activity achieved by TQ-CS-PLGA-NPs and TQ-PLGA-NPs was due to the higher solubility of TQ in PLGA, CS, and TPGS present in the NPs.

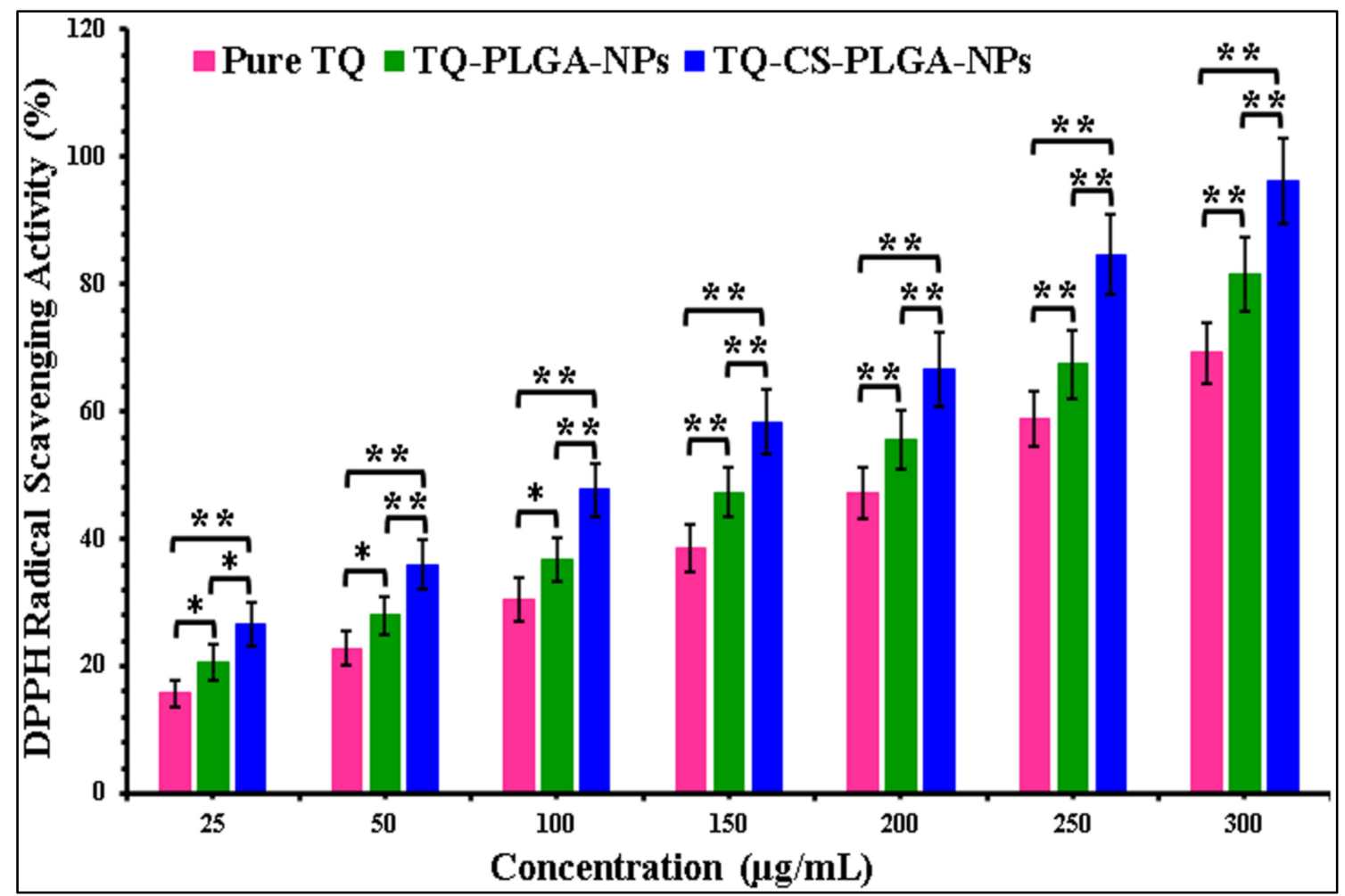

Figure 7. Comparative antioxidant activity of TQ-CS-PLGA-NPs, TQ-PLGA-NPs, and pure thymoquinone (TQ). Results are expressed as percentage mean $\pm \mathrm{SD}(n=3) .{ }^{*}$ and ${ }^{* *}$ represent significant and highly significant difference to different groups.

\subsection{Cell Viability Assay}

The potential outcomes of the cytotoxicity study in MDA-MB-231 and MCF-7 cells are represented in Figure 8, which clearly demonstrates that TQ-CS-PLGA-NPs and TQ-PLGANPs showed statistically higher concentrations and time-dependent cytotoxicity compared to pure TQ at $24 \mathrm{~h}$ and $48 \mathrm{~h}$ of study. The $\mathrm{IC}_{50}$ value of TQ-CS-PLGA-NPs, TQ-PLGA-NPs, and pure TQ was found to be $4.36 \mu \mathrm{M}, 5.42 \mu \mathrm{M}$, and $8.24 \mu \mathrm{M}$, respectively, after $24 \mathrm{~h}$ of treatment against MDA-MB-231 cells (Figure $8 \mathrm{~A}$ ). After $48 \mathrm{~h}$ of treatment, the $\mathrm{IC}_{50}$ value of TQ-CS-PLGA-NPs, TQ-PLGA-NPs, and pure TQ was found to be $3.12 \mu \mathrm{M}, 4.26 \mu \mathrm{M}$, and $6.58 \mu \mathrm{M}$, respectively (Figure $8 \mathrm{~B}$ ). The $\mathrm{IC}_{50}$ value of the TQ-CS-PLGA-NPs, TQ-PLGA$\mathrm{NPs}$, and pure TQ was found to be $52.54 \mu \mathrm{M}, 58.16 \mu \mathrm{M}$, and $63.78 \mu \mathrm{M}$, respectively, after $24 \mathrm{~h}$ of treatment in MCF-7 cells (Figure 8C). After $48 \mathrm{~h}$ of treatment, the $\mathrm{IC}_{50}$ value of TQ-CS-PLGA-NPs, TQ-PLGA-NPs, and pure TQ was found to be $47.72 \mu \mathrm{M}, 49.94 \mu \mathrm{M}$, and $54.67 \mu \mathrm{M}$, respectively (Figure $8 \mathrm{D}$ ). As per the MTT assay results, a much better result was found in TQ-CS-PLGA-NP-treated cells. This can be explained by the fact that the CS-PLGA-NPs revealed significantly higher delayed TQ release compared to TQ-PLGANPs, which produces an excellent cellular response [47]. Among the two cancerous cell 
lines used in the study, the obtained $\mathrm{IC}_{50}$ values indicated that TQ-CS-PLGA-NPs and TQPLGA-NPs were most potent towards both tested cell lines. Our results are corroborated by a previously published report [48].

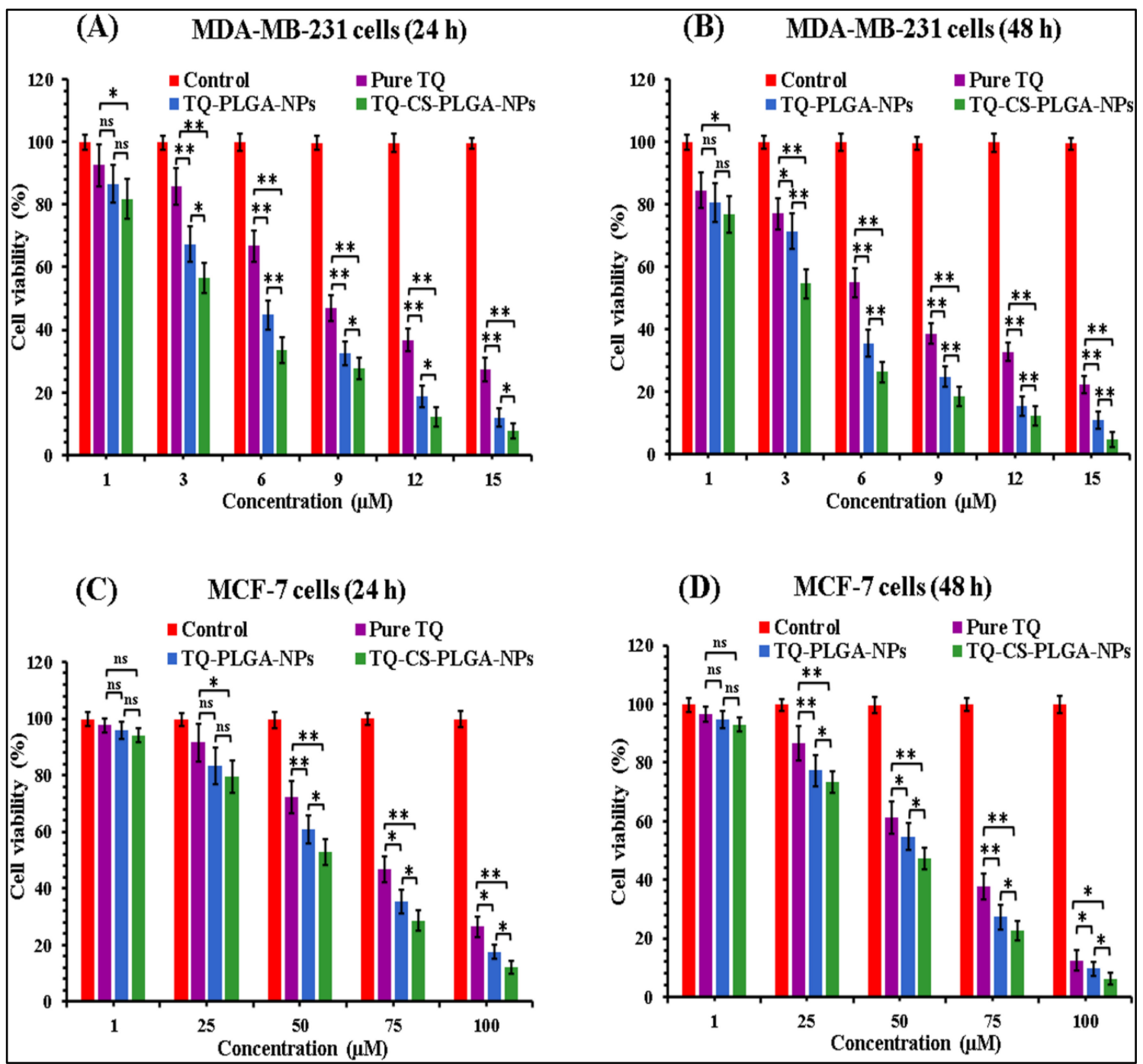

Figure 8. Comparative cytotoxicity study of TQ-Cs-PLGA-NPs, TQ-PLGA-NPs, and pure TQ against (A) MDA-MB-231 cells after 24 h; (B) MDA-MB-231 cells after 48 h; (C) MCF-7 cells after 24 h; (D) MCF-7 cells after 48 h. Results are expressed as percentage mean $\pm \mathrm{SD}(n=3){ }^{*}$ and ${ }^{* *}$ represent significant and highly significant difference to different groups.

\subsection{Ex Vivo Intestinal Permeation Study}

Figure 9A,B clearly reveal that a significantly higher quantity of TQ permeated and transported through the intestinal sac from optimized TQ-CS-PLGA-NPs and TQ-PLGANPs in comparison to TQ suspension. As per our findings, TQ-CS-PLGA-NPs exhibited about 1.92- and 3.15-fold higher $\mathrm{P}_{\text {app }}$ compared to TQ-PLGA-NPs and TQ suspension. The reason for the enhancement in $\mathrm{P}_{\mathrm{app}}$ was due to the presence of TPGS in the NPs as an excipient, which is a potent P-glycoprotein efflux pump inhibitor that was present on the mucous membrane of GIT [49]. Furthermore, the mucoadhesive nature of TQ-CS-PLGANPs also led to the disruption and/or modulation of tightness in the tight junctions of the gastrointestinal mucosa. Due to the positive charge due to coating with CS, NPs interact with negatively charged gastrointestinal mucosa that leads to the opening of tight junctions. Therefore, a significantly higher quantity of drug permeated across the mucosa [26]. 


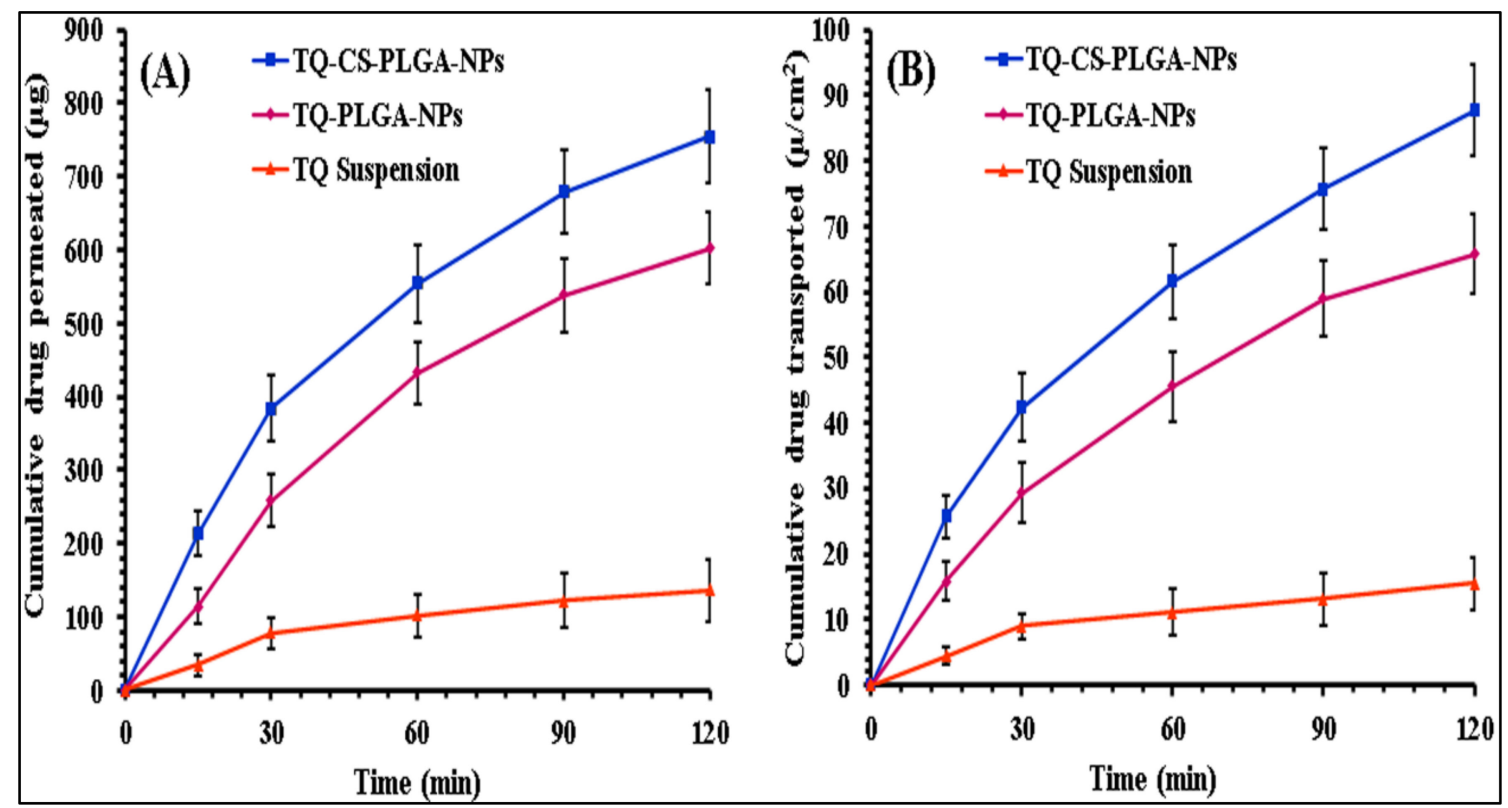

Figure 9. Ex vivo intestinal permeation study result showing: (A) cumulative amount of drug permeated ( $\mu \mathrm{g})$ vs. time, (B) cumulative drug transported $\left(\mu \mathrm{g} \mathrm{cm}^{-2}\right)$ vs. time.

\section{Conclusions}

TQ-CS-PLGA-NPs were fabricated successfully for improved TQ delivery and efficacy against breast cancer cells. The PS and PDI of the developed TQ-CS-PLGA-NPs were satisfactory, and the \%EE of TQ in the NPs was observed to be greater than $78 \%$. The TQ-CS-PLGA-NPs showed excellent gastrointestinal as well as colloidal stability. The TEM micrograph showed a spherical shape with uniform particle distribution and smooth surface. The CS coating provided modulation in TQ release from the NPs and exhibited a sustained release profile up to $24 \mathrm{~h}$. The TQ-CS-PLGA-NPs showed significantly higher antioxidant activity compared to TQ-PLGA-NPs and pure TQ. Furthermore, TQ-CS-PLGANPs exhibited much higher intestinal permeation compared to the uncoated TQ-PLGANPs and pure TQ suspension. Therefore, our developed TQ-CS-PLGA-NPs represents an excellent mucoadhesive nanoformulation to combat the challenges of TQ for improved delivery and in vitro efficacy against breast cancer.

Author Contributions: Conceptualization, S.S.I. and S.A.; methodology, S.S.I., K.U.F. and M.R.; software, M.R.; validation, S.S.I. and M.R.; formal analysis, W.M.; investigation, S.S.I. and S.A.; data curation, S.S.I., M.R. and K.U.F.; writing—original draft preparation, S.S.I. and M.R.; writing—review and editing, M.K., W.M. and M.M.A.R.; visualization, M.M.A.R. and S.A.; supervision, S.A. and M.M.A.R.; project administration, S.A. and S.S.I.; funding acquisition, S.A. All authors have read and agreed to the published version of the manuscript.

Funding: Deputyship for Research and Innovation, "Ministry of Education" in Saudi Arabia (project number IFKSURG-1438-013).

Data Availability Statement: Data is contained within the article.

Acknowledgments: The authors extend their appreciation to the Deputyship for Research and Innovation, "Ministry of Education" in Saudi Arabia for funding this research work through the project number IFKSURG-1438-013.

Conflicts of Interest: The authors declare no conflict of interest. 


\section{References}

1. Francies, F.Z.; Hull, R.; Khanyile, R.; Dlamini, Z. Breast cancer in low-middle income countries: Abnormality in splicing and lack of targeted treatment options. Am. J. Cancer Res. 2020, 10, 1568-1591. [PubMed]

2. Rizwanullah, M.; Alam, M.; Harshita; Mir, S.R.; Rizvi, M.M.A.; Amin, S. Polymer-lipid hybrid nanoparticles: A next-generation nanocarrier for targeted treatment of solid tumors. Curr. Pharm. Des. 2020, 26, 1206-1215. [CrossRef] [PubMed]

3. Elmowafy, M.; Samy, A.; Raslan, M.A.; Salama, A.; Said, R.A.; Abdelaziz, A.E.; El-Eraky, W.; El Awdan, S.; Viitala, T. Enhancement of bioavailability and pharmacodynamic effects of thymoquinone via nanostructured lipid carrier (NLC) formulation. AAPS PharmSciTech. 2016, 17, 663-672. [CrossRef] [PubMed]

4. Khan, M.A.; Tania, M.; Fu, S.; Fu, J. Thymoquinone, as an anticancer molecule: From basic research to clinical investigation. Oncotarget 2017, 8, 51907-51919. [CrossRef] [PubMed]

5. Ballout, F.; Habli, Z.; Rahal, O.N.; Fatfat, M.; Gali-Muhtasib, H. Thymoquinone-based nanotechnology for cancer therapy: Promises and challenges. Drug Discov. Today 2018, 23, 1089-1098. [CrossRef]

6. Khan, F.A.; Rizwanullah, M.; Perwez, A.; Ahmad, M.Z.; Ahmad, J. Polymeric Nanomedicines in Treatment of Breast Cancer: Review of Contemporary Research. Front. Anti-Cancer Drug Discov. 2020, 11, 36-66.

7. Danhier, F.; Ansorena, E.; Silva, J.M.; Coco, R.; Le Breton, A.; Préat, V. PLGA-based nanoparticles: An overview of biomedical applications. J. Control. Release 2012, 161, 505-522. [CrossRef]

8. Rezvantalab, S.; Drude, N.I.; Moraveji, M.K.; Güvener, N.; Koons, E.K.; Shi, Y.; Lammers, T.; Kiessling, F. PLGA-Based Nanoparticles in Cancer Treatment. Front. Pharmacol. 2018, 9, 1260. [CrossRef]

9. Kumar, G.; Shafiq, N.; Malhotra, S. Drug-loaded PLGA nanoparticles for oral administration: Fundamental issues and challenges ahead. Crit. Rev. Ther. Drug Carrier Syst. 2012, 29, 149-182. [CrossRef] [PubMed]

10. Chen, H.; Xie, L.Q.; Qin, J.; Jia, Y.; Cai, X.; Nan, W.; Yang, W.; Lv, F.; Zhang, Q.Q. Surface modification of PLGA nanoparticles with biotinylated chitosan for the sustained in vitro release and the enhanced cytotoxicity of epirubicin. Colloids Surf. B Biointerfaces 2016, 138, 1-9. [CrossRef] [PubMed]

11. Zhang, X.; Sun, M.; Zheng, A.; Cao, D.; Bi, Y.; Sun, J. Preparation and characterization of insulin loaded bioadhesive PLGA nanoparticles for oral administration. Eur. J. Pharm. Sci. 2012, 45, 632-638. [CrossRef] [PubMed]

12. Wang, Y.; Li, P.; Kong, L. Chitosan modified PLGA nanoparticles with versatile surface for improved drug delivery. AAPS PharmSciTech. 2013, 14, 585-592. [CrossRef] [PubMed]

13. Alqahtani, S.; Simon, L.; Astete, C.E.; Alayoubi, A.; Sylvester, P.W.; Nazzal, S.; Shen, Y.; Xu, Z.; Kaddoumi, A.; Sabliov, C.M. Cellular uptake, antioxidant and antiproliferative activity of entrapped $\alpha$-tocopherol and $\gamma$-tocotrienol in poly(lactic-co-glycolic) acid (PLGA) and chitosan covered PLGA nanoparticles(PLGA-Chi). J. Colloid. Interface Sci. 2015, 445, 243-251. [CrossRef] [PubMed]

14. Lima, I.A.; Khalil, N.M.; Tominaga, T.T.; Lechanteur, A.; Sarmento, B.; Mainardes, R.M. Mucoadhesive chitosan-coated PLGA nanoparticles for oral delivery of ferulic acid. Artif. Cells Nanomed. Biotechnol. 2018, 46, 993-1002. [CrossRef]

15. Chuah, L.H.; Billa, N.; Roberts, C.J.; Burley, J.C.; Manickam, S. Curcumincontaining chitosan nanoparticles as a potential mucoadhesive delivery system to the colon. Pharm. Dev. Technol. 2013, 18, 591-599. [CrossRef]

16. Gilani, S.J.; Imam, S.S.; Ahmed, A.; Chauhan, S.; Mirza, M.A.; Taleuzzaman, M. Formulation and evaluation of thymoquinone niosomes: Application of developed and validated RP-HPLC method in delivery system. Drug Dev. Ind. Pharm. 2019, 4, 1799-1806. [CrossRef]

17. Rizwanullah, M.; Amin, S.; Ahmad, J. Improved pharmacokinetics and antihyperlipidemic efficacy of rosuvastatin-loaded nanostructured lipid carriers. J. Drug Target. 2017, 25, 58-74. [CrossRef]

18. Khatoon, K.; Rizwanullah, M.; Amin, S.; Mir, S.R.; Akhter, S. Cilnidipine loaded transfersomes for transdermal application: Formulation optimization, in-vitro and in-vivo study. J. Drug Deliv. Sci. Tech. 2019, 54, 101303. [CrossRef]

19. Abd El Hady, W.E.; Mohamed, E.A.; Soliman, O.A.; El-Sabbagh, H.M. In vitro-in vivo evaluation of chitosan-PLGA nanoparticles for potentiated gastric retention and anti-ulcer activity of diosmin. Int. J. Nanomed. 2019, 14, 7191-7213. [CrossRef]

20. Shahab, M.S.; Rizwanullah, M.; Alshehri, S.; Imam, S.S. Optimization to development of chitosan decorated polycaprolactone nanoparticles for improved ocular delivery of dorzolamide: In vitro, ex vivo and toxicity assessments. Int. J. Biol. Macromol. 2020, 163, 2392-2404. [CrossRef]

21. Saifi, Z.; Rizwanullah, M.; Mir, S.R.; Amin, S. Bilosomes nanocarriers for improved oral bioavailability of acyclovir: A complete characterization through in vitro, ex-vivo and in vivo assessment. J. Drug Deliv. Sci. Tech. 2020, 57, 101634. [CrossRef]

22. Kaithwas, V.; Dora, C.P.; Kushwah, V.; Jain, S. Nanostructured lipid carriers of olmesartan medoxomil with enhanced oral bioavailability. Colloids Surf. B Biointerfaces 2017, 154, 10-20. [CrossRef] [PubMed]

23. Dalmoro, A.; Bochicchio, S.; Nasibullin, S.F.; Bertoncin, P.; Lamberti, G.; Barba, A.A.; Moustafine, R.I. Polymer-lipid hybrid nanoparticles as enhanced indomethacin delivery systems. Eur. J. Pharm. Sci. 2018, 121, 16-28. [CrossRef] [PubMed]

24. Soni, K.; Rizwanullah, M.; Kohli, K. Development and optimization of sulforaphane-loaded nanostructured lipid carriers by the Box-Behnken design for improved oral efficacy against cancer: In vitro, ex vivo and in vivo assessments. Artif. Cells Nanomed. Biotechnol. 2018, 46, 15-31. [CrossRef] [PubMed]

25. Filipović-Grčić, J.; Škalko-Basnet, N.; Jalšienjak, I. Mucoadhesive chitosan-coated liposomes: Characteristics and stability. J. Microencapsul. 2001, 18, 3-12. [CrossRef] [PubMed] 
26. Fakhria, A.; Gilani, S.J.; Imam, S.S. Formulation of thymoquinone loaded chitosan nano vesicles: In-vitro evaluation and in-vivo anti-hyperlipidemic assessment. J. Drug Deliv. Sci. Technol. 2019, 50, 339-346. [CrossRef]

27. Imam, S.S.; Alshehri, S.; Alzahrani, T.A.; Hussain, A.; Altamimi, M.A. Formulation and Evaluation of Supramolecular Food-Grade Piperine HP $\beta$ CD and TPGS Complex: Dissolution, Physicochemical Characterization, Molecular Docking, In Vitro Antioxidant Activity, and Antimicrobial Assessment. Molecules 2020, 25, 4716. [CrossRef]

28. Khan, M.A.; Zafaryab, M.; Mehdi, S.H.; Quadri, J.; Rizvi, M.M. Characterization and carboplatin loaded chitosan nanoparticles for the chemotherapy against breast cancer in vitro studies. Int. J. Biol. Macromol. 2017, 97, 115-122. [CrossRef]

29. Al-Joudi, F.S.; Alias, I.Z.; Samsudin, A.R. The effects of chemotherapeutic drugs on viabilty, apoptosis, and survivin expression in MCF-7 cells. Acta Histochem. Cytochem. 2005, 38, 323-330. [CrossRef]

30. Jahangir, M.A.; Khan, R.; Imam, S.S. Formulation of sitagliptin-loaded oral polymeric nano scaffold: Process parameters evaluation and enhanced anti-diabetic performance. Artif. Cells Nanomed. Biotechnol. 2018, 46, 66-78. [CrossRef]

31. Barkat, M.A.; Rizwanullah, M.; Beg, S.; Pottoo, F.H.; Siddiqui, S.; Ahmad, F.J. Paclitaxel-loaded nanolipidic carriers with improved oral bioavailability and anticancer activity against human liver carcinoma. AAPS PharmSciTech. 2019, $20,87$.

32. Lepeltier, E.; Bourgaux, C.; Couvreur, P. Nanoprecipitation and the "Ouzo effect": Application to drug delivery devices. Adv. Drug Deliv. Rev. 2014, 71, 86-97. [CrossRef] [PubMed]

33. Tavares, M.R.; de Menezes, L.R.; Dutra Filho, J.C.; Cabral, L.M.; Tavares, M.I. Surface-coated polycaprolactone nanoparticles with pharmaceutical application: Structural and molecular mobility evaluation by TD-NMR. Polym. Test. 2017, 60, 39-48. [CrossRef]

34. Zafar, A.; Khan, N.; Alruwaili, N.K.; Bukhari, S.N.; Alsuwayt, B.; Afzal, M.; Akhtar, S.; Yasir, M.; Elmowafy, M.; Shalaby, K.; et al. Improvement of Ocular Efficacy of Levofloxacin by Bioadhesive Chitosan Coated PLGA Nanoparticles: Box-behnken Design, In-vitro Characterization, Antibacterial Evaluation and Scintigraphy Study. Iran. J. Pharm. Res. 2020, 19, $292-311$.

35. Mishra, A.; Imam, S.S.; Aqil, M.; Ahad, A.; Sultana, Y.; Ameeduzzafar; Ali, A. Carvedilolnano lipid carriers: Formulation, characterization and in-vivo evaluation. Drug Deliv. 2016, 23, 1486-1494. [CrossRef]

36. Khan, N.; Khanna, K.; Bhatnagar, A.; Ahmad, F.J.; Ali, A. Chitosan coated PLGA nanoparticles amplify the ocular hypotensive effect of forskolin: Statistical design, characterization and in vivo studies. Int. J. Biol. Macromol. 2018, 116, 648-663. [CrossRef] [PubMed]

37. Sharma, N.; Madan, P.; Lin, S. Effect of process and formulation variables on the preparation of parenteral paclitaxel-loaded biodegradable polymeric nanoparticles: A cosurfactant study. Asian J. Pharm. Sci. 2016, 11, 404-416. [CrossRef]

38. Sathyamoorthy, N.; Magharla, D.; Chintamaneni, P.; Vankayalu, S. Optimization of paclitaxel loaded poly ( $\varepsilon$-caprolactone) nanoparticles using Box Behnken design. Beni-Suef Univ. J. Basic Appl. Sci. 2017, 6, 362-373. [CrossRef]

39. Shah, M.; Pathak, K. Development and Statistical Optimization of Solid Lipid Nanoparticles of Simvastatin by Using 2(3) Full-Factorial Design. AAPS PharmSciTech. 2010, 11, 489-496. [CrossRef]

40. Liu, D.; Pan, H.; He, F.; Wang, X.; Li, J.; Yang, X.; Pan, W. Effect of particle size on oral absorption of carvedilol nanosuspensions: In vitro and in vivo evaluation. Int. J. Nanomedicine 2015, 10, 6425-6434. [CrossRef]

41. Lu, B.; Lv, X.; Le, Y. Chitosan-modified PLGA nanoparticles for control-released drug delivery. Polymers 2019, 11, 304. [CrossRef] [PubMed]

42. Simoes, S.; Figueiras, A.; Veiga, F.; Concheiro, A.; Alvarez-Lorenzo, C. Polymeric micelles for oral drug administration enabling locoregional and systemic treatments. Expert Opin. Drug Deliv. 2014, 12, 297-318. [CrossRef] [PubMed]

43. Anwer, M.K.; Mohammad, M.; Ezzeldin, E.; Fatima, F.; Alalaiwe, A.; Iqbal, M. Preparation of sustained release apremilast-loaded PLGAnanoparticles: In vitro characterization and in vivo pharmacokinetic study in rats. Int. J. Nanomed. 2019, 14, 1587-1595. [CrossRef] [PubMed]

44. Kim, B.S.; Kim, C.S.; Lee, K.M. The intracellular uptake ability of chitosan-coated poly (D,L-lactideco-glycolide) nanoparticles. Arch. Pharm. Res. 2008, 31, 1050-1054. [CrossRef]

45. Sogias, I.A.; Williams, A.C.; Khutoryanskiy, V.V. Why is chitosan mucoadhesive? Biomacromolecules 2008, 9, 1837-1842. [CrossRef]

46. Zarai, Z.; Boujelbene, E.; Ben Salem, N.; Gargouri, Y.; Sayari, A. Antioxidant and antimicrobial activities of various solvent extracts, piperine and piperic acid from Piper nigrum. LWT Food Sci. Technol. 2013, 50, 634-641. [CrossRef]

47. Chronopoulou, L.; Massimi, M.; Giardi, M.F.; Cametti, C.; Devirgiliis, L.C.; Dentini, M.; Palocci, C. Chitosan coated PLGA nanoparticles: A sustained drug release strategy for cell cultures. Colloids Surf. B Biointerfaces 2013, 103, 310-317. [CrossRef]

48. Ng, W.K.; Yazan, L.S.; Yap, L.H.; Wan Nor Hafiza, W.A.G.; How, C.W.; Abdullah, R. Thymoquinone-loaded nanostructured lipid carrier exhibited cytotoxicity towards breast cancer cell lines (MDA-MB-231 and MCF-7) and cervical cancer cell lines (HeLa and SiHa). Biomed. Res. Int. 2015, 2015, 263131. [CrossRef]

49. Ahmad, J.; Mir, S.R.; Kohli, K.; Chuttani, K.; Mishra, A.K.; Panda, A.K.; Amin, S. Solid-nanoemulsion preconcentrate for oral delivery of paclitaxel: Formulation design, biodistribution, and $\gamma$-scintigraphy imaging. Biomed. Res. Int. 2014, $2014,984756$. [CrossRef] 